\title{
FINANCEIRIZAÇÃO DA ESTRATÉGIA: UM ESFORÇO PARA MAPEAMENTO DE SEU DESENVOLVIMENTO VIA ANÁLISE BIBLIOMÉTRICA
}

Com o desenvolvimento de uma concepção financeira da empresa, o conceito de Geração de Valor ao Acionista tem se desenvolvido e consolidado. Tal conceito apregoa que o propósito principal da empresa é maximizar a riqueza do acionista - e seus desdobramentos, levam a um processo de Financeirização da Estratégia, no qual as estratégias empresariais se veem impactadas por dita racionalidade financeira. Assim, o objetivo deste trabalho é realizar pesquisa bibliométrica para explorar o campo de pesquisa da Financeirização da Estratégia, e com isto elaborar um panorama geral inicial da produção científica na área, para subsidiar futuras pesquisas no campo. Os resultados indicam que (1) existe uma quantidade relevante de produção científica sobre o tema que não vem sendo publicada sob o rótulo de financeirização; (2) embora o processo de financeirização tenha suas raízes em teoria econômica anterior, o estudo da Financeirização da Estratégia é relativamente recente; (3) a questão da Geração de Valor ao Acionista parece ser o tema central nas pesquisas relacionadas à Financeirização da Estratégia; (4) a pesquisa na área parece ser bastante dispersa, pois não se identifica um autor, ou conjunto de autores, que seja extremamente expressivo na área e (5) os principais canais de publicação destas pesquisas também são dispersos, e além de periódicos voltados a finanças e à estratégia, tal pesquisa também é veiculada em jornais de marketing

Palavras-Chave: Financeirização da Estratégia, Geração de Valor ao Acionista, Gestão Baseada em Valor, Pesquisa Bibliométrica.

\section{STRATEGY FINANCIALIZATION: AN EFFORT TO MAP ITS DEVELOPMENT BY MEANS OF BIBLIOMETRIC RESEARCH}

With the development of a financial theory of the firm, the concept of Shareholder Value Generation has developed and consolidated. This concept advocates that the main purpose of the firm is to maximize shareholder's wealth, and its consequences lead to a process of strategy financialization in which business strategies are impacted by such financial rationality. The goal of this paper is to carry out bibliometric research to explore the field of Strategy Financialization, producing an initial overview of the scientific production in the area, to support future research in the field. The results indicate that (1) there is a significant amount of scientific literature on the subject that has not been published under the label of financialization ; (2) although the financialization process has its roots in previous economic theory, the study of Strategy Financialization is relatively recent ; (3) the issue of Shareholder Value Creation seems to be the central theme in research related to Strategy Financialization; (4) research in the area seems to be quite scattered, once that it has not identified an author or group of authors, that are extremely significant in the area and (5) the main publication vehicles are also dispersed, including not only typical finance and strategy journal, but also marketing journals.

Keywords: Strategy Financialization; Shareholder Value; Value Based Management; Bibliometric Research.

\footnotetext{
${ }^{1}$ Fundação Getúlio Vargas - EAESP FGV, Brasil

E-mail: jonasmaia.dr.eng@outlook.com

2 Fundação Getúlio Vargas - EAESP FGV, Brasil

E-mail: luiz.diserio@fgv.br
} 


\section{INTRODUÇÃO}

Ao longo das últimas décadas, as discussões macroeconômicas têm presenciado o surgimento e crescimento do debate sobre a configuração de um novo modelo de acumulação dentro do capitalismo, centrado em temas financeiros em lugar de temas típicos de produção. Nesse âmbito, se o regime de acumulação de capital é a forma pela qual o sistema capitalista leva ao crescimento da economia, no "regime de acumulação dominado pelas finanças" (conforme expressão cunhada por Chesnais, 2002), o processo de acumulação poderia se dar mais fortemente dentro da esfera financeira, com (1) a reaparição maciça das receitas resultantes dos títulos de dívida e ações, e (2) o papel representado pelos mercados financeiros na determinação de consumo, investimento e emprego (Chesnais, 2008).

Dentro do contexto deste regime capitalista dominado pelas finanças, um processo particularmente relevante parece ocorrer, o qual tem sido denominado de financeirização. De acordo com Stockhammer (2012), o termo "financeirização" tem adquirido sentido na medida em que retrata diversas mudanças no relacionamento entre os setores "financeiro" e "real" (entendido aqui pelo da produção de bens e serviços). Em uma definição ampla do processo de financeirização, Epstein $(2005$, p. 3) a coloca como "o papel crescente de motivos financeiros, mercados financeiros, atores financeiros e instituições financeiras na operação das economias domésticas e internacionais".

Froud et al (2012) consideram a edição especial de 2000 do periódico Economy and Society como o marco inicial da literatura sobre financeirização. Dentro desta edição especial, o editorial de Karel Williams de Universidade de Manchester (Reino Unido) é referenciado como o trabalho seminal dentro da área. Embora os próprios conceitos, e também uma série de artigos relacionados, já houvessem sido publicados antes daquela oportunidade, Williams (2000, citado por Froud et al, 2012) foi o primeiro a utilizar a expressão "Financeirização".

Se todo o contexto dos agentes econômicos é alterado pelo dito "capitalismo dominado pelas finanças" e sobretudo pela financeirização, é legítimo considerar que as empresas e suas preocupações microeconômicas e administrativas também sejam fortemente impactadas por esse contexto mais amplo. De particular interesse dentro deste estudo, as estratégias trabalhadas por estas empresas também devem haver sido impactas pelo mencionado processo de financeirização, mudando os principais objetivos e padrões de decisão dentro das firmas.

Em uma pesquisa preliminar, Maia e Di Serio (2014) identificaram a necessidade de esforços acadêmicos para melhor conectar a financeirização com as estratégias empresariais, dado que poucas pesquisas pareciam focar o inter-relacionamento entre ambos os conceitos, sendo que financeirização parecia permanecer apenas no âmbito da Macroeconomia, com pouca ou nenhuma conexão com a Administração de Empresas, onde a estratégia se insere.

$\mathrm{O}$ interesse deste artigo, assim, reside no processo que fica conhecido como "Financeirização da Estratégia", o qual justamente busca trabalhar o interrelacionamento mencionado acima ao considerar o papel crescente das motivações, pressões e atores financeiros dentro das estratégias das organizações.

No contexto do esforço para trabalhar a conexão entre as duas áreas e seus conceitos, Froud et al (2012) indicam que no nível da firma, a financeirização se traduz principalmente pelo impacto sobre os gestores corporativos para acomodar as pressões por valor ao acionista e as revisões da estratégia e políticas de investimento. Dessa forma, assim como também é corroborado por Maia e Di Serio (2014), a Geração de Valor ao Acionista é termo chave quando se deseja compreender, analisar e pesquisar a conexão entre financeirização e estratégia empresarial.

Assim, o objetivo deste trabalho é realizar uma pesquisa bibliométrica para explorar o campo de pesquisa da Financeirização da Estratégia, avaliando a produção científica dos artigos publicados acerca de tal tema na base de indexação do Web of Science. Desta forma, planeja-se obter uma caracterização descritiva desta base contemplando aspectos como principais trabalhos, autores, local de publicação, temas e palavras-chave de pesquisa, entre outros. Este panorama geral descritivo deveria ilustrar a situação atual da pesquisa sobre o tema, e permitir a identificação de novas lacunas a serem trabalhadas bem como novos avanços a serem dados dentro deste campo de conhecimento.

A justificativa para tal estudo decorre da busca por suprir uma lacuna de entendimento de como a pesquisa científica vem se desenvolvendo e comportando dentro desta área, uma vez que estudos preliminares identificaram que embora haja uma produção relevante em financeirização, e que sua conexão com estratégia seria algo teoricamente esperado, a produção acadêmica em financeirização é na prática pouco relacionada ao campo da estratégia. Desta forma, essa constatação inicial precisa ser validada por meio de uma pesquisa com maior embasamento metodológico, que consiga contextualizar tal produção ao longo do tempo, identificando os principais autores (elite acadêmica) e os temas correlatos que têm sido desenvolvidos. Este entendimento abre um leque relevante de pesquisa para os eventuais gaps identificados, trazendo possibilidade de avanços para aquilo que já está sendo estudado, e abrindo oportunidades de explorar aquilo que ainda não tem sido trabalhado. 
Também, deve-se registrar que estratégia é um tema extremamente plural, amplo e que ultrapassa as fronteiras internas da empresa, estando relacionada aos objetivos e às contribuições de todas as funções da empresa (marketing, recursos humanos, finanças, operações, etc.). Este trabalho, assim, se insere em um conjunto de pesquisas que buscam explorar as conexões das estratégias empresariais com outras áreas específicas do conhecimento em administração apenas para mencionar alguns: a integração entre marketing e estratégia (Zinkhan e Verbrugge, 2000 prefácio da edição especial da Journal of Business Strategy, totalmente devotada ao tema, além de Guerrazzi et al, 2015 ); entre recursos humanos e estratégia (Schuler e Jackson, 1987 e Bird e Beechler, 1995); entre operações e estratégia (Hayes e Wheelwright, 1984; Slack, 2005). Similarmente, a relação das finanças com outras áreas da empresa também tem sido estudada, como por exemplo o trabalho de Srivastava (1998), que trabalha com a interface finanças e marketing ao analisar ativos de marketing (relacionamento com clientes, com canais e com parceiros) e como estes aumentam a Geração de Valor ao Acionista.

Entretanto, justamente por essa característica pervasiva e ampla da estratégia, é necessário registrar que neste trabalho a "estratégia" será compreendida dentro de seu contexto tradicional da área de conhecimento de Estratégias Empresariais dentro da Administração de Empresas. Em outras palavras, embora fosse tentador tentar abarcar também conceitos de áreas de Marketing, Operações, Recursos Humanos, etc., dado que estes também têm conexões com a estratégia, opta-se por aqui não fazê-lo, com o objetivo de evitar um aumento exagerado de escopo com possível prejuízo a qualidade das conclusões aqui obtidas.

O artigo se encontra assim estruturado: inicialmente são apresentadas rápidas sínteses teóricas sobre os conceitos de Financeirização da Estratégia e Geração de Valor ao Acionista. Depois são apresentadas as etapas metodológicas e os dados da pesquisa bibliométrica propriamente dita. Esta foi realizada em duas "formas", uma primeira apenas com os termos Financeirização e Estratégia, que não produziu os resultados esperados, e foi revisada para inserir também termos relacionados à financeirização. Sobre estas pesquisas são indicadas as análises de citações e referências, autores e instituições, referencias e periódicos, temas e palavras-chave. Por fim, são indicadas as considerações finais e principais conclusões preliminares do trabalho.

\section{REFERENCIAL TEÓRICO}

Conforme mencionado na introdução desse trabalho, o conceito de Financeirização se origina principalmente em discussões macroeconômicas acerca do modelo de produção capitalista, mas traz implicações bastante importantes para a gestão das empresas. Dessa forma, duas características seriam particularmente relevantes dentro deste novo modelo capitalista "dominado pelas finanças": (1) reaparição maciça das receitas resultantes dos títulos de dívida e ações, (2) papel representado pelos mercados financeiros na determinação de consumo, investimento e emprego (Chesnais, 2008).

Como um processo se desenvolvendo dentro deste contexto maior de uma nova forma de capitalismo, a "financeirização" tem adquirido sentido na medida em que retrata diversas mudanças no relacionamento entre os setores "financeiro" e "real" (Stockhammer, 2012). O sentido e aplicação do termo têm sido bastante amplos, retratando desde a orientação à Geração de Valor ao Acionista retratado na subseção anterior, aumento na dívida imobiliária (sobretudo nos Estados Unidos), aumento do resultado decorrente de operações financeiras, aumento da frequência de crises financeiras e aumento da mobilidade internacional do capital.

Embora trabalhos clássicos como de Adam Smith, Karl Marx, entre outros, possam ser entendidos como os primeiros trabalhos sobre financeirização, Stockhammer (2012) considera o trabalho de Arrighi (1994) como um dos primeiros a utilizar tal termo em específico. Segundo aquele autor, as ondas de desenvolvimento econômico são caracterizadas por movimentos ascendentes de atividade de produção, e descendentes de financeirização das atividades, conforme os lideres da etapa ascendente têm seu modelo exaurido.

Embora estabelecer uma definição para "financeirização" não seja tarefa fácil, duas definições serão aqui apresentadas para guiar o desenvolvimento do trabalho. A primeira já foi antecipada na introdução, e é particularmente relevante por ser bastante ampla e assim se prestar a amplitude de compreensão encerrada pelo termo financeirização: como Epstein (2005, p. 3) define, a financeirização é "o papel crescente de motivos financeiros, mercados financeiros, atores financeiros e instituições financeiras na operação das economias domésticas e internacionais”. A segunda, por outro lado, busca ser um pouco mais específica e talvez mais pragmática: para Dias e Zilbovicius (2006, p.1), financeirização pode ser compreendida como "um processo no qual a valorização do capital via sistema financeiro é apreciada em detrimento da valorização do capital via produção, a tal ponto que as consideradas boas práticas de organização e gestão da produção passam a refletir as boas práticas valorizadas do mundo financeiro - liquidez, volatilidade, flexibilidade - e que os próprios sistemas de produção tendem a ser julgados com critérios comumente utilizados em ambientes puramente financeiros, a esfera produtiva subordinando-se, assim, à esfera financeira". Estes mesmos autores, ao traçarem uma linha evolutiva da 
gestão da produção, destacam um início Fordista no qual a produção seria a principal fonte de lucro da empresa e a efetiva geradora de valor agregado, e uma nova realidade no qual a produção é apenas mais uma forma de valorização do capital (dentre outras diversas possíveis).

Uma vez apresentadas possíveis definições para a financeirização, o foco agora recai sobre compreender exatamente quais podem ser os impactos produzidos pela mesma, nas diferentes esferas econômicas. Dessa forma, três áreas distintas são relevantes para menção: (1) efeitos da financeirização no nível macro, tratando temas como acumulação, declínio dos retornos do investimento produtivo, mudança do capital de produtivo para financeiro, entre outros - de alguma forma similar à primeira frente proposta por Wood e Wright (2007); (2) efeitos da financeirização no nível da firma, focando o papel dos gestores corporativos em acomodar as pressões por valor ao acionista e as revisões da estratégia e políticas de investimento; (3) efeitos da financeirização em si mesma, com abordagens neomarxistas ou foucaldianas, enfatizando como a financeirização se torna embarcada nas práticas do dia-a-dia, alterando percepções sobre responsabilidades e riscos (Froud et al, 2012).

Neste trabalho o segundo aspecto acima mencionado é o de maior relevância, na medida em que os efeitos da financeirização sobre as firmas são os que, em primeiro nível, tendem a se constituir em forças direcionadoras sobre a estratégia. Dessa forma, as pressões pela Geração de Valor ao Acionista passam a ser encaradas como uma das formas de tradução e ponto de confluência entre a financeirização e as estratégias das empresas. Assim, os próximos parágrafos se ocupam em melhor compreender o desenvolvimento dos conceitos de geração de valor.

O conceito da Geração de Valor ao Acionista se embasa em uma "visão financeira" da empresa, de alguma forma distinta às visões tradicionais de governança e organização. Esta "concepção financeira da empresa”, de acordo com Di Maggio (2001), começa a se consolidar no início da década de 1980 e apresenta a firma como um portfólio de ativos, portfólio este que deve ter seu desempenho maximizado pelo corpo executivo da empresa. Cada ativo deve ter seu desempenho metodológica e sistematicamente avaliado, e uma série de ações devem ser empreendidas para que o portfólio total seja cada vez mais rentável, mesmo que isto implique na liquidação de um ativo.

Essa concepção inicial da empresa sob a ótica financeira, ao longo da década de 80 evolui para uma série de proposições de gestão, acerca de como a empresa deveria ser administrada neste contexto. Surge assim, o conceito de Geração de Valor ao Acionista que, conforme colocado por Fligstein (2002), sua principal ideia é que o único propósito efetivamente legítimo da firma é maximizar o valor (entendido pela geração de riqueza) a seu acionista.
O próprio conceito de Geração de Valor ao Acionista, aliado ao pressuposto de que a função do corpo executivo da empresa é unicamente gerar tal valor, levam a construção de um outro conceito que é a Gestão Baseada em Valor (do inglês, value based management). Por esse conceito, toda a gestão da empresa precisa estar focada justamente na Geração de Valor ao Acionista, e o alinhamento da ação entre todos os níveis da empresa é feito por uma série de elementos, como: plano de remuneração focado na geração de valor, um mindset (forma de pensar) voltado para agregação de valor ao acionista e a criação de uma cultura de "senso de dono", como se cada gestor fosse também acionista do negócio (Martin \& Petty, 2001; Young \& O’Byrne, 2000).

Para "operacionalizar" o conceito da gestão pela geração de valor, diversas ferramentas têm sido apresentadas. Talvez a mais conhecida, Ehrbar (1999) traz o EVA (uma ferramenta proprietária para a gestão de valor), menciona que este contribui para a gestão efetiva da empresa ao menos de duas formas: (1) cobrando das operações o custo de capital, o que obriga os gerentes a utilizar seus ativos com maior cuidado e diligência, agregando uma "última linha de despesa" antes que os gestores possam de fato julgar que suas operações são lucrativas; e (2) elimina algumas distorções contábeis que não se prestam ao julgamento gerencial do resultado financeiro, como a capitalização de investimentos em pesquisa e desenvolvimento, a amortização de ágio, etc.

Uma vez compreendida a financeirização e a geração do valor ao acionista, o foco recai sobre o que se espera da estratégia dentro deste contexto. Para Smit e Trigeorgis (2004), a busca pela criação de valor (premissa e produto do processo de financeirização) implica que a estratégia da empresa deveria levar em conta os direcionadores de valor relevantes, de forma que a combinação destes direcionadores, recursos e opções reais gerariam o posicionamento estratégico favorável para a empresa.

Além de atuar sobre os direcionadores correspondentes, a utilização eficiente dos investimentos em capital passa também a ser uma das principais preocupações da estratégia. Conforme Andersson, Haslam, Lee e Tsitsianis (2010) colocam, o direcionamento dos novos trabalhos em Financeirização da Estratégia é que, em uma era de Geração de Valor ao Acionista, a conjuntura aumenta a pressão sobre os gestores em extrair o maior retorno possível sobre o capital empregado, eventualmente mudando seu modelo de negócios para aumentar o valor do acionista e aumentar a probabilidade de uma maior valorização das ações e acumulação de riqueza pelos acionistas. Andersson, Haslam, Lee, Katechos e Tsitsianis (2008, p. 263) destaca "o objetivo da estratégia corporativa, na era do valor para o acionista, é fortalecer os resultados financeiros operativos e aumentar a probabilidade de acumulação de riqueza 
pelos acionistas no mercado de capitais como valor de mercado".

Dessa forma, considerando o mencionado processo de Financeirização da Estratégia, e a Geração de Valor ao Acionista, o presente trabalho busca realizar uma pesquisa bibliométrica para explorar dito campo de pesquisa. As seções seguintes apresentam o método e os resultados obtidos com este levantamento bibliométrico.

\section{MÉTODO DE PESQUISA}

Conforme previamente mencionado, será empregada a análise bibliométrica para atingir o objetivo planejado para este trabalho. De acordo com Pritchard (1969), as pesquisas bibliométricas podem se prestar ao menos a 5 propósitos distintos: (1) identificar grandes tendências e bases de crescimento do conhecimento em uma determinada área científica, (2) avaliar grau de dispersão e obsolescência de determinados assuntos, (3) medir impacto de publicação de trabalhos, estudos e informações e sua disseminação no ambiente acadêmico, (4) quantificar a amplitude de cobertura de determinados periódicos científicos e (5) identificar níveis de produtividade de autores e instituições. Desta forma, estes propósitos estão extremamente alinhados ao objetivo do trabalho aqui apresentado.

A bibliometria se embasa em pelo menos três distintas leis sobre a distribuição bibliométrica. Embora não seja objetivo aqui aprofundar em tais leis, sucintamente pode-se colocar (Vanti, 2002 e Guedes \& Borschiver, 2005): (1) a Lei de Lotka, que almeja medir a produtividade dos autores, identificar centros de pesquisa desenvolvidos em determinada área e reconhecer a solidez de um determinado campo científico; (2) a Lei de Zipf, que mede a frequência de determinadas palavras nos textos, produzindo assim uma lista de termos dentro de uma disciplina, conforme sua relevância - dessa forma, a concentração de palavras com alto conteúdo semântico poderia ser usada como forma de indexação do texto devido a sua representatividade dentro da temática; (3) a Lei de Bradford, que mede a produtividade dos periódicos estimando sua relevância dentro de uma determinada área do conhecimento - periódicos com maior número de artigos acerca de um determinado tema formam, supostamente, um conjunto de veículos com maior relevância para certa área.

Utilizando as leis acima apresentadas, foi definida uma sequência de etapas para a execução da análise bibliométrica deste trabalho, conforme apresentado na Figura 1.

\section{Obtenção dos dados}

A primeira etapa se refere à consulta propriamente dita, executada dentro de uma base de indexação de trabalhos. Dentre as diversas bases disponíveis, foi selecionada a base de dados Web of Science (WoS), publicada pela Thomson Reuters, dado que essa possui boa abrangência para pesquisas na área de Administração de Empresas, e indexa periódicos de grande reconhecimento, com modelo de peer review e alto impacto em pesquisa (Maia e Di Serio, 2015).

Por meio da interface de consulta do WoS são armadas expressões Booleanas que reflitam logicamente o escopo da pesquisa pretendido, utilizando a base de "Core Collection" do WoS. A próxima seção que trará a representação dos dados obtidos irá ilustrar, para cada pesquisa, o conjunto de palavras-chave utilizado.

A segunda etapa compreende a aplicação dos devidos filtros, de tipos de publicação, área de conhecimento, lapso de tempo, etc., para correta delimitação da amostra de trabalhos a ser estudada. $\mathrm{O}$ objetivo com esta fase reside em evitar que trabalhos que tenham sido selecionados dentro da amostra "por acaso" interfiram nas análises que serão posteriormente realizadas, distorcendo assim os possíveis resultados e conclusões obtidas.

\section{Procedimentos de Análise}

A terceira etapa contempla a análise descritiva e temporal dos artigos obtidos na amostra, contextualizando a produção científica (publicações e citações) no tempo e identificando os principais trabalhos na área. Para tanto são extraídas as informações diretamente dos relatórios do WoS, e estas são carregadas no Microsoft Excel para a realização de análises de estatística descritiva e a construção de gráficos para visualização dos resultados.

A quarta etapa se embasa na Lei de Lotka para identificar os autores, instituições e países mais relevantes, utilizando rankings e mapas de cocitação. Além das análises descritivas pelo Microsoft Excel, para esta atividade será utilizado também o software VOSViewer (Van Eck \& Waltman, 2010) que aplica algoritmos de agrupamento e modelos de criação de gráficos para a construção de redes (como a de cocitação) que apresentem informações úteis sobre o conhecimento no tema pesquisado.

A etapa seguinte analisa onde o tema vem sendo publicado, baseando-se na Lei de Bradford, para identificar os principais periódicos, áreas de pesquisa, etc. A sexta etapa utiliza a Lei de Zipf para analisar as principais palavras-chave na indexação dos trabalhos da amostra, bem como os principais termos que podem ser identificados nos artigos, retratando quais conceitos são trabalhados conjuntamente e como estes se relacionam. Para a análise de palavras-chave, o arquivo 
extraído do WoS foi processado de forma que pudesse gerar uma planilha eletrônica específica com as palavras desejadas. A análise dos termos se utiliza de uma função do VOSViewer que busca os termos no Título e Resumo dos artigos da amostra, classificando- os conforme a importância e gerando a rede de relacionamento entre eles.

Por fim, os resultados de todas estas etapas são conjuntamente analisados e são produzidas as principais conclusões sobre a pesquisa.

Figura 1- Etapas metodológicas da pesquisa.

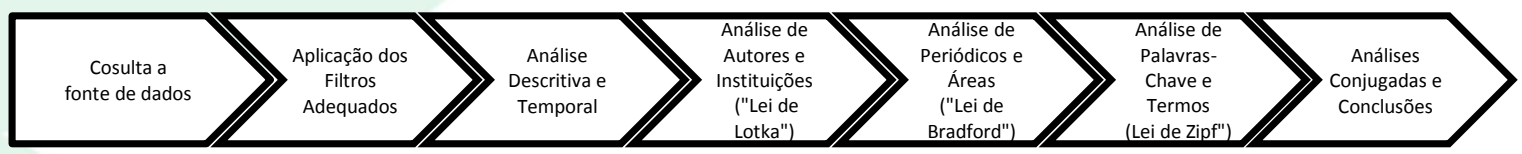

Fonte: Elaborado pelos autores.

Para fins de enquadramento metodológico, esta pesquisa pode ser classificada como exploratória e descritiva, almejando descrever as características de um determinado fenômeno por meio da coleta de dados acerca de seu estado atual (Gay \& Diehl, 1992). No que tange à abordagem do problema, esta pesquisa pode ser classificada como combinado entre qualitativa e quantitativa. Para Bryman (1989), a pesquisa quantitativa contempla a coleta e análise de dados de forma estruturada, para interpretar parâmetros de interesse para a investigação. A pesquisa qualitativa, por outro lado, caracteriza-se por um foco maior na compreensão dos dados que na sua mensuração, sendo aplicada em casos nos quais a riqueza de detalhes é mais relevante que as informações quantitativas (Richardson, 1985).

\section{PESQUISA BIBLIOMÉTRICA 1: Sem termos relacionados}

O processo de busca de documentos foi executado tendo como base nas seguintes palavraschave: "financialization" OR "financialisation" AND "strategy". A partir deste resultado, os documentos foram refinados em critérios de busca de acordo com a Tabela 2. Desta busca e refino, foram obtidas apenas 42 publicações.

Tabela 2 - Filtros com critérios de busca

\begin{tabular}{|c|c|}
\hline Tipo & Artigos ou trabalhos de congresso. \\
\hline $\begin{array}{c}\text { Expressão de busca de } \\
\text { Palavras chave }\end{array}$ & $\begin{array}{c}\text { ("Financialization" OU "Financialisation") } \\
\text { E "Strategy" }\end{array}$ \\
\hline Áreas de conhecimento & Sem restrições \\
\hline Tempo & Sem restrições \\
\hline
\end{tabular}

Fonte: Elaborado pelos autores.

\section{Análise descritiva de citações e referências}

A figura 3 ilustra o ano de publicação dos artigos, para dar indicativo da produção de conhecimento ao longo do tempo. Como pode ser observado, o número de publicações começa a crescer apenas a partir de 2009, mas como a amostra é pequena, as variações não são relevantes em termos absolutos. Mesmo este crescimento depois de 2009 deve ser colocado em perspectiva, pois conforme afirma Neely(2005), a base do Web of Science possui mais informações sobre publicações mais recentes e recentemente existe uma tendência de aumento na quantidade de publicações acadêmicas. 
Figura 3- Número de publicações por ano.

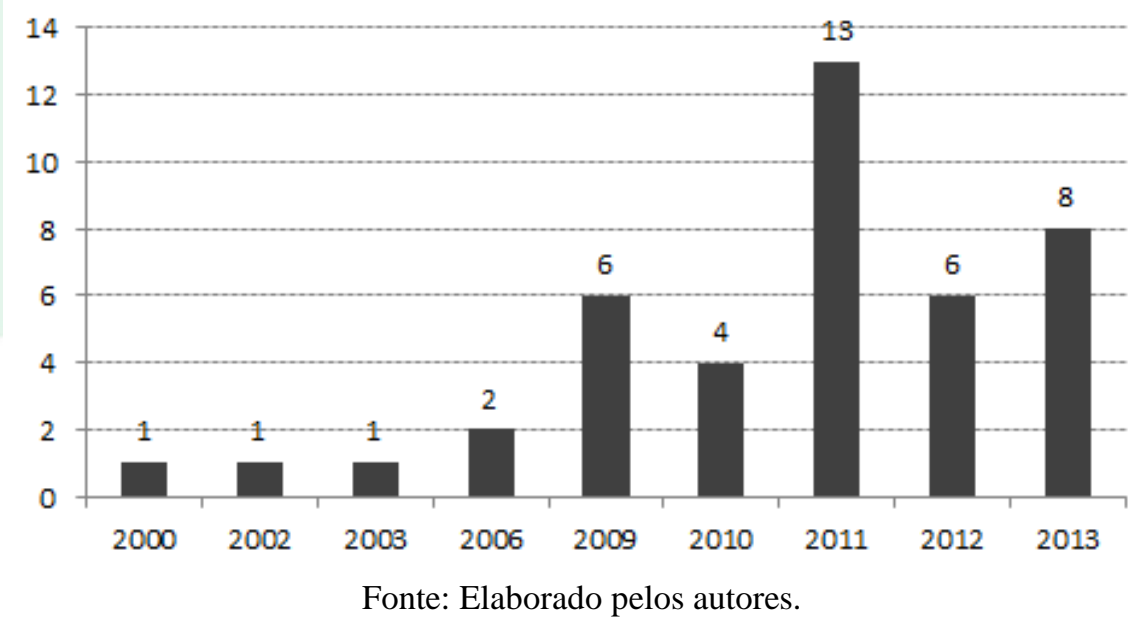

De forma complementar, a Figura 4 ilustra a quantidade de citações para os artigos da pesquisa ao longo de cada um dos anos. Da observação pode-se identificar que a maior parte das citações ocorre no

período iniciado em 2012, totalizando $47 \%$ do total de citações. Similarmente às próprias publicações, existe uma maior tendência de os artigos da pesquisa serem referenciados nos últimos anos.

Figura 4- Número de citações aos artigos da amostra por ano.

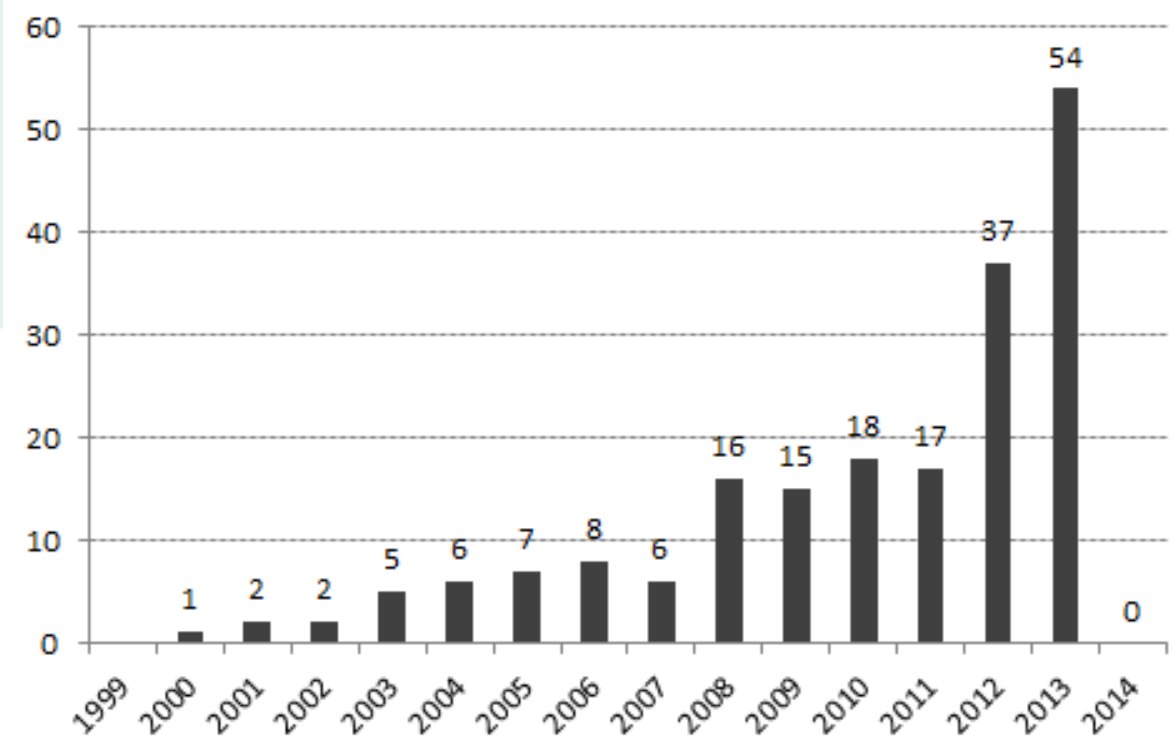

Fonte: Elaborado pelos autores.

Buscando trazer maior detalhamento, a tabela 5 apresenta as publicações que apresentam maior número de citação aos artigos da amostra. Pode-se observar que a maioria dos artigos se relaciona a temas econômicos generalistas, como capitalismo, neoliberalismo, regime de acumulação. Nesta mesma linha, os principais periódicos nos quais tais publicações figuram são relacionados à Economia, Geopolítica, Política, entre outros. 
Financeirização da Estratégia: Um Esforço para Mapeamento de seu Desenvolvimento Via Análise Bibliométrica

Tabela 5 - Publicações com maior número de citação à amostra

\begin{tabular}{|c|c|c|c|}
\hline Nro Citações & Autores & Título & Publicação \\
\hline 61 & Williams, K & $\begin{array}{l}\text { From shareholder value to } \\
\text { present-day capitalism }\end{array}$ & $\begin{array}{c}\text { ECONOMY AND SOCIETY Volume: } \\
29 \text { Issue: } 1 \text { Pages:1-12 } \\
\end{array}$ \\
\hline 26 & Lazzarato, Maurizio & $\begin{array}{l}\text { Neoliberalism in Action } \\
\text { Inequality, Insecurity and the } \\
\text { Reconstitution of the Social }\end{array}$ & $\begin{array}{l}\text { THEORY CULTURE \& SOCIETY } \\
\text { Volume: } 26 \text { Issue: } 6 \text { Pages:109-133 }\end{array}$ \\
\hline 23 & Finlayson, Alan & $\begin{array}{c}\text { Financialisation, Financial } \\
\text { Literacy and Asset-Based } \\
\text { Welfare }\end{array}$ & $\begin{array}{l}\text { BRITISH JOURNAL OF POLITICS } \\
\& \text { INTERNATIONAL RELATIONS } \\
\text { Volume: } 11 \text { Issue: } 3 \text { Pages:400-421 }\end{array}$ \\
\hline 14 & $\begin{array}{l}\text { O'Neill, P; McGuirk, } \\
\text { P }\end{array}$ & $\begin{array}{l}\text { Prosperity along Australia's } \\
\text { eastern seaboard: Sydney and } \\
\text { the geopolitics of urban and } \\
\text { economic change }\end{array}$ & $\begin{array}{l}\text { AUSTRALIAN GEOGRAPHER } \\
\text { Volume: } 33 \text { Issue: } 3 \text { Pages:241-261 }\end{array}$ \\
\hline 13 & Smart, A; Lee, J & $\begin{array}{l}\text { Financialization and the role } \\
\text { of real estate in Hong Kong's } \\
\text { regime of accumulation }\end{array}$ & $\begin{array}{c}\text { ECONOMIC GEOGRAPHY Volume: } \\
79 \text { Issue: } 2 \text { Pages: } 153-171\end{array}$ \\
\hline 8 & $\begin{array}{l}\text { Onaran, Ozlem; } \\
\text { Stockhammer, } \\
\text { Engelbert; Grafl, } \\
\text { Lucas }\end{array}$ & $\begin{array}{l}\text { Financialisation, income } \\
\text { distribution and aggregate } \\
\text { demand in the USA }\end{array}$ & $\begin{array}{c}\text { CAMBRIDGE JOURNAL OF } \\
\text { ECONOMICS Volume: } 35 \text { Issue: } 4 \\
\text { Pages:637-661 }\end{array}$ \\
\hline 6 & $\begin{array}{l}\text { Wainwright, } \\
\text { Thomas }\end{array}$ & $\begin{array}{l}\text { Tax doesn't have to be taxing: } \\
\text { London's 'onshore' finance } \\
\text { industry and the fiscal spaces } \\
\text { of a global crisis }\end{array}$ & $\begin{array}{l}\text { ENVIRONMENT AND PLANNING } \\
\text { A Volume: } 43 \text { Issue: } 6 \text { Pages:1287- } \\
1304\end{array}$ \\
\hline 6 & Kaedtler, Juergen & $\begin{array}{c}\text { Financialisation of Capitalist } \\
\text { Economies - Bargaining on } \\
\text { Conventional Economic } \\
\text { Rationalities }\end{array}$ & $\begin{array}{l}\text { HISTORICAL SOCIAL RESEARCH- } \\
\text { HISTORISCHE } \\
\text { SOZIALFORSCHUNG Volume: } 36 \\
\text { Issue: } 4 \text { Pages:169-191 }\end{array}$ \\
\hline 6 & Palpacuer, Florence & $\begin{array}{l}\text { The global sourcing patterns } \\
\text { of French clothing retailers }\end{array}$ & $\begin{array}{c}\text { ENVIRONMENT AND PLANNING } \\
\text { A Volume: } 38 \text { Issue: } 12 \text { Pages:2271- } \\
2283 \\
\end{array}$ \\
\hline 4 & Rolnik, Raquel & $\begin{array}{c}\text { Late Neoliberalism: The } \\
\text { Financialization of } \\
\text { Homeownership and Housing } \\
\text { Rights }\end{array}$ & $\begin{array}{l}\text { INTERNATIONAL JOURNAL OF } \\
\text { URBAN AND REGIONAL } \\
\text { RESEARCH Volume: } 37 \text { Issue: } 3 \\
\text { Pages:1058-1066 }\end{array}$ \\
\hline
\end{tabular}

Fonte. Elaborada pelos autores

Análise descritiva de autores e instituições

A tabela 6 ilustra os principais autores dos trabalhos obtidos via a pesquisa bibliométrica. Podese notar, em alguma medida, certa dispersão da produção bibliográfica no tema, dado que os cinco principais autores não chegam a reunir $30 \%$ dos trabalhos da amostra. Destaque fica para os autores Adam Leaver e Karel Williams, da Universidade de Manchester no Reino Unido, que se apresentam como os dois mais profícuos.

Tabela 6 - Autores mais profícuos

\begin{tabular}{|c|c|c|}
\hline Autores & Nro Trabalhos & \% \\
\hline Leaver A & 3 & $7 \%$ \\
\hline Williams K & 3 & $7 \%$ \\
\hline Froud J & 2 & $5 \%$ \\
\hline Johal S & 2 & $5 \%$ \\
\hline Krige D & 2 & $5 \%$ \\
\hline Outros & 30 & $71 \%$ \\
\hline
\end{tabular}

Fonte: Elaborado pelos autores. 
Derivada da análise dos pesquisadores, as tabelas 7 e 8 apresentam as universidades cujos autores mais publicaram no tema, e o respectivo país no qual são sediadas. As universidades de Londres e de Manchester são as que mais publicam no tema,

Tabela 7 - Instituições mais profícuas

\begin{tabular}{ccc} 
Organização & Trabalhos & \% \\
\hline University Of London & 4 & $10 \%$ \\
\hline University Of Manchester & 4 & $10 \%$ \\
\hline Kingston University & 3 & $7 \%$ \\
\hline Complutense Univ Of Madrid & 2 & $5 \%$ \\
\hline Universidade De Sao Paulo & 2 & $5 \%$ \\
\hline Outros & 27 & $64 \%$ \\
\hline
\end{tabular}

Fonte: Elaborado pelos autores.

\section{Análise das referências e periódicos}

A figura 9 mostra a análise de cocitações das referências trazidas na pesquisa bibliométrica. Esta análise busca identificar a quantidade de vezes que dois trabalhos são citados simultaneamente em um mesmo artigo, denotando proximidade temática entre autores e redes de pesquisa. Foram produzidos cinco clusters distintos; o A, centralizado no trabalho de Greta Krippner sobre a financeirização da economia americana, publicado em 2005 na Socio-Economic chegando juntas a quase $20 \%$ do total das publicações. Com isso, a Inglaterra se mostra o país de maior produção científica na área, com mais de $30 \%$ das publicações.

Figura 9 - Diagrama de Cocitações

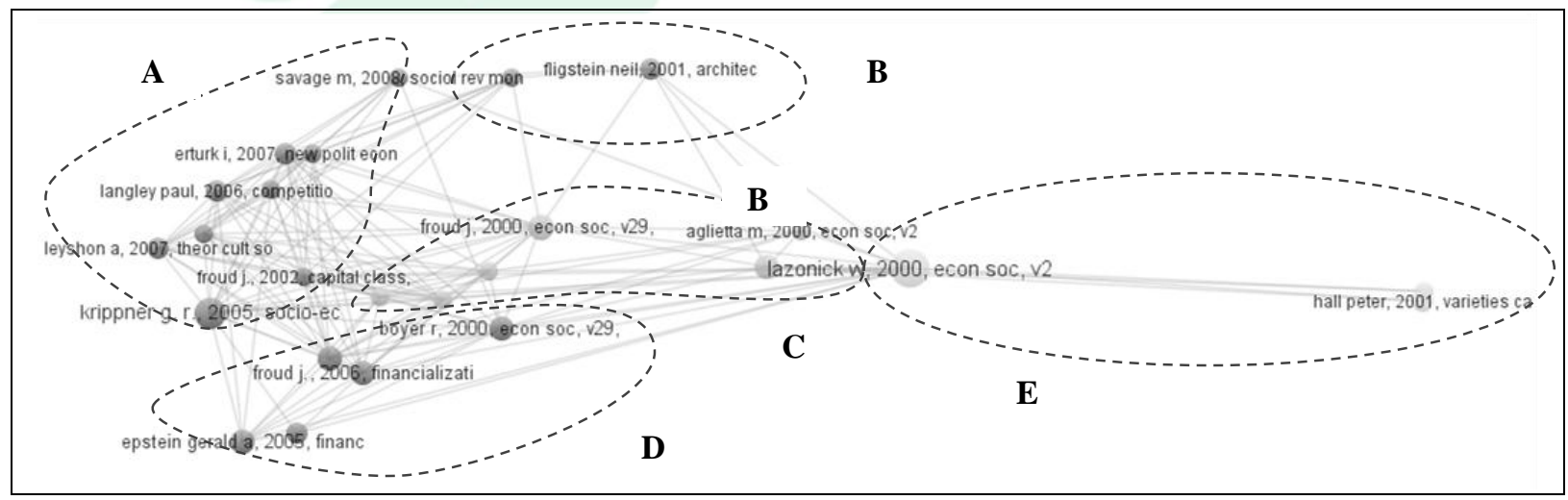

Fonte: Elaborado pelos autores.

A tabela 10 apresenta os periódicos nos quais os artigos mais referenciados pelos trabalhos da pesquisa foram publicados. Similarmente ao já comentado anterior, os principais periódicos são enfocados em economia, sociedade e geopolítica, e a distribuição
Tabela 8 - Países mais profícuos

\begin{tabular}{ccc}
\hline Países & Nro Trabalhos & $\mathbf{\%}$ \\
\hline Inglaterra & 13 & $31 \%$ \\
\hline Estados Unidos & 7 & $17 \%$ \\
\hline França & 4 & $10 \%$ \\
\hline Africa do Sul & 3 & $7 \%$ \\
\hline Brasil & 2 & $5 \%$ \\
\hline Outros & 13 & $31 \%$ \\
\hline
\end{tabular}

Fonte: Elaborado pelos autores.

Review; o B, com o livro de Julie Froud de 2006 sobre financeirização, com textos teóricos e alguns casos e números sobre o fenômeno; o $\mathrm{C}$, com o trabalho de Julie Froud e coautores sobre a posição dos consultores e gestores no contexto da financeirização e também o trabalho de William Lazonick e Mary O’Sullivan sobre a ideologia da maximização do valor ao acionista, publicado em 2000 na Economy and Society; e por fim os clusters D e E, com trabalhos de Neil Fligstein e de Peter Hall sobre arquitetura de mercados e variedades de capitalismo, respectivamente. 
Tabela 10 - Periódicos mais citados

\begin{tabular}{|c|c|c|}
\hline Países & Nro Trabalhos & $\%$ \\
\hline Socio Economic Review & 3 & $7 \%$ \\
\hline Envoroment and Planning & 3 & $7 \%$ \\
\hline Economy and Society & 3 & $7 \%$ \\
\hline Geopolitics & 2 & $5 \%$ \\
\hline Amercian Ethnologist & 1 & $2 \%$ \\
\hline Outros & 30 & $71 \%$ \\
\hline
\end{tabular}

Fonte: Elaborado pelos autores.

\section{Análises de Termos e Palavras-Chave}

A figura 11 traz a frequência das palavras-chave nos artigos obtidos por meio desta pesquisa bibliométrica. Um primeiro ponto importante a destacar é que o software não é capaz de normalizar/padronizar as palavras-chave, como se evidencia com "Financialization" e "Financialisation" (apenas diferentes grafias decorrentes do inglês americano e do inglês britânico). Como estas palavras claramente representam um mesmo tema, elas seriam a palavra-chave mais presente, com 25 citações, como seria de se esperar pela própria delimitação da pesquisa. As demais palavras apresentam conceitos diferentes relacionados à gestão pelo valor, crises econômicas, governança, neoliberalismo, capitalismo, etc.

Utilizando a função de identificação de termos do VOSViewer, que busca termos tanto no título quanto no resumo dos artigos, foi construído o diagrama de relacionamento de termos. Contudo, nenhum outro termo relevante, diferente de Estratégia e Financeirização, emergiu..

Figura 11 - Frequência das palavras-chave

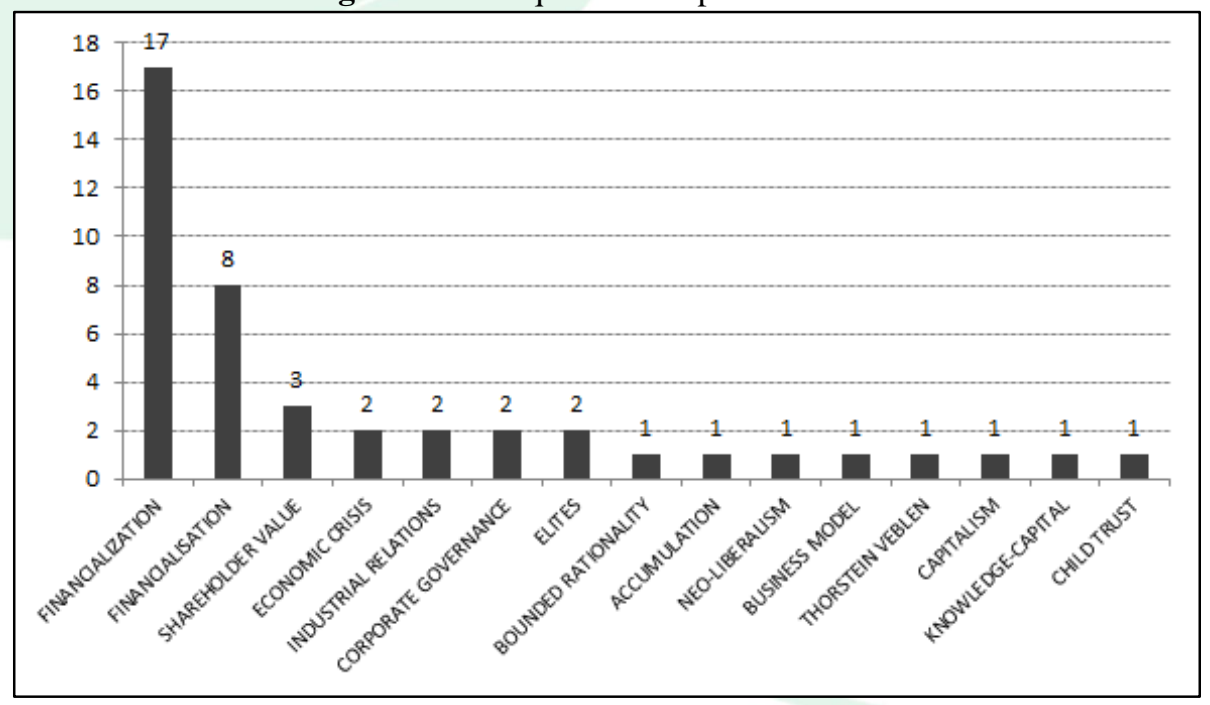

Fonte: Elaborado pelos autores.

\section{Discussão preliminar dos resultados e a necessidade de reorientação da pesquisa}

Conforme fica evidenciado pelas seções anteriores, a pesquisa bibliométrica original, apenas com os termos Financeirização e Estratégia, não atinge os objetivos planejados.

Primeiro, a amostra obtida foi extremamente pequena, resultando em pouco mais de 40 publicações de todo o universo. Segundo, mesmo as quantidades de citações também são restritas, tendo o pico de $54 \mathrm{em}$ 2013. Se comparado a outras pesquisas similares, que também tratam de campos iniciais de pesquisa, geralmente tem-se acima de 80 resultados na amostra, e 200 citações por ano (Maia \& Alves Filho, 2014; Maia, Martins \& Maia, 2013). Terceiro, do que se pode depreender dos artigos mais citados, o foco dos trabalhos geralmente recai sobre temas gerais de 
Economia (capitalismo, neoliberalismo, etc.) e não sobre Estratégias Empresariais, como se planejava inicialmente para a pesquisa. Quarto, e corroborando, o terceiro ponto, os veículos de publicação também são relacionados a temas econômicos amplos, e não a Administração e Estratégia. Quinto, excetuando as próprias palavras-chave "financialization" e "financialisation", todas as demais palavras tem frequência menor a três, o que denota de alguma forma dispersão entre os próprios temas.

Assim, a pesquisa será replicada com a utilização de palavras-chave adicionais relacionadas à Geração de Valor ao Acionista para garantir aderência ao foco de pesquisa. Optou-se, contudo, por manter esses dados nesta publicação, pois eles de alguma forma sugerem que embora se esteja pesquisando financeirização das estratégias, isto não tem ocorrido sob esta denominação. Este fato será mais aprofundado nas análises e conclusões do estudo.

\section{PESQUISA BIBLIOMÉTRICA 2: Com termos relacionados}

O processo de busca de documentos foi novamente executado com base nas seguintes palavraschave: "financialization" ou "financialisation" ou "shareholder value" ou EVA ou "economic value added" ou "value-based" ou "value-driven" $\mathrm{e}$ "strategy". A partir deste resultado, os documentos foram refinados em critérios de busca de acordo com a Tabela 12. Desta busca e refino, foram obtidas 408 publicações.

Tabela 12 - Filtros com critérios de busca

\begin{tabular}{|c|c|}
\hline Tipo & Artigos ou trabalhos de congresso. \\
\hline $\begin{array}{l}\text { Expressão de busca de } \\
\text { Palavras chave }\end{array}$ & $\begin{array}{c}\text { ("Financialization" OR "Financialisation" OR "shareholder } \\
\text { value" OR EVA OR "economic value added" OR "value- } \\
\text { based" OR "value-driven") AND "strategy". }\end{array}$ \\
\hline Áreas de conhecimento & $\begin{array}{c}\text { Business, Public Administration, Management, Economics, } \\
\text { Operations Research, Management Science, Business } \\
\text { Finance, Industrial Engineering, Sociology. }\end{array}$ \\
\hline Tempo & Sem restrições \\
\hline
\end{tabular}

Análise descritiva de citações e referências

O ano de publicação dos artigos é indicado na figura 13. Como pode ser observado, o número de publicações tem aumentado ao longo dos últimos anos, principalmente de 2008 para frente, pois este período concentra $63 \%$ do total de publicações, com uma média de 42,5 publicações por ano. Contudo, novamente vale a ressalva de Neely (2005), sobre o comportamento da base do Web of Science quanto a publicações recentes.

Figura 13 - Número de publicações por ano.

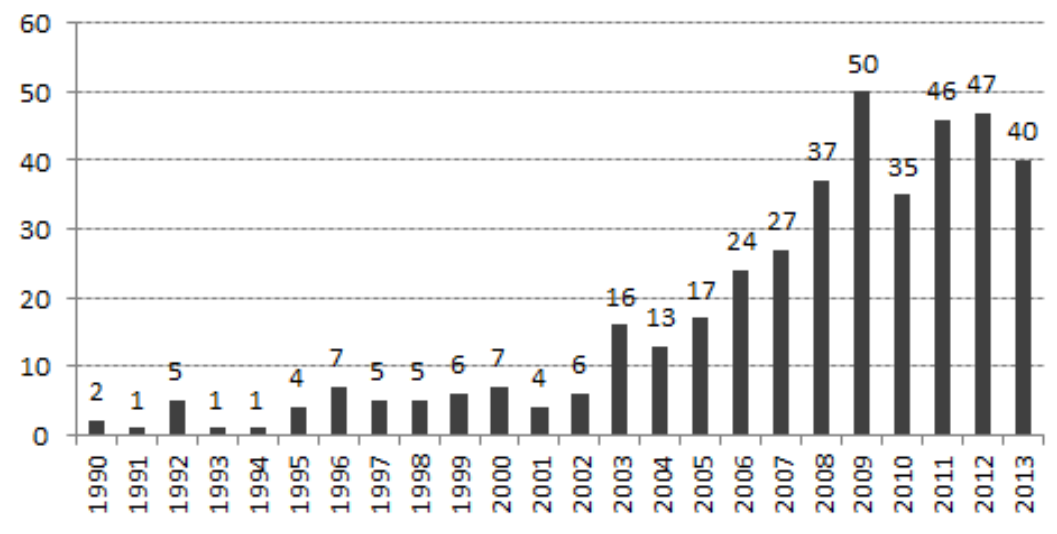

Fonte: Elaborado pelos autores.

A Figura 14 ilustra a quantidade de citações para os artigos da pesquisa ao longo de cada um dos anos. Similarmente, da observação pode-se identificar que a maior parte das citações ocorre no período iniciado em 2008, totalizando $81 \%$ do total de citações e com uma média de 652 citações por ano.

Figura 14 - Número de citações aos artigos da amostra por ano. 
Financeirização da Estratégia: Um Esforço para Mapeamento de seu Desenvolvimento Via Análise Bibliométrica

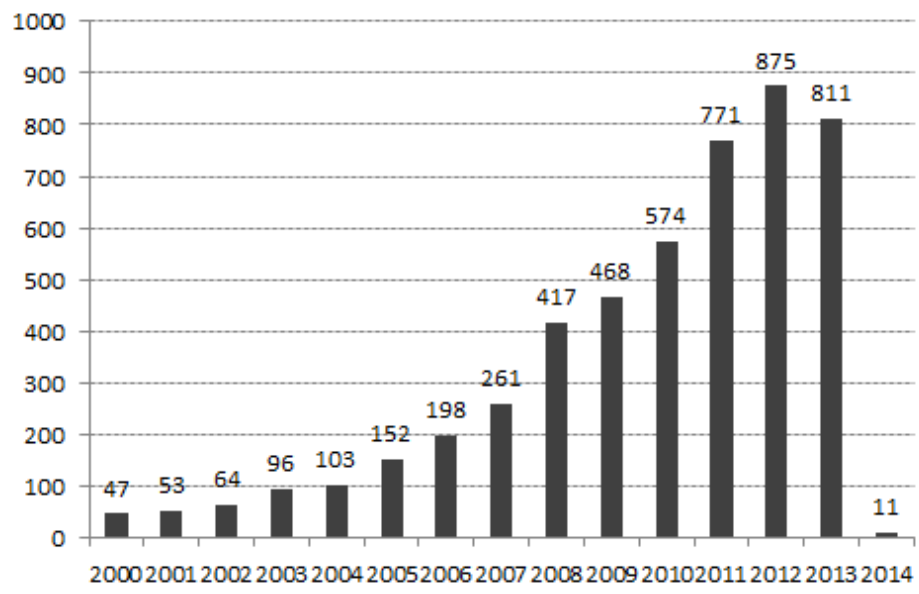

Fonte: Elaborado pelos autores.

A tabela 15 apresenta as publicações que apresentam maior de citações. Com esta reorientação da pesquisa bibliométrica, as publicações parecem mais aderentes ao propósito da pesquisa. Em sua maioria, os artigos lidam com o tema da Geração de Valor ao
Acionista, e com algumas outras aplicações específicas dentro da administração. Vale ressaltar que nenhum dos trabalhos presentes na primeira tentativa reapareceu nesta nova versão.

Tabela 15 - Publicações com maior número de citação à amostra

\begin{tabular}{|c|c|c|c|}
\hline Nro Citações & Autores & Título & Publicação \\
\hline 329 & $\begin{array}{l}\text { Sinkula, JM; } \\
\text { Baker, WE; } \\
\text { Noordewier, T }\end{array}$ & $\begin{array}{l}\text { A framework for market-based } \\
\text { organizational learning: Linking } \\
\text { values, knowledge, and behavior }\end{array}$ & $\begin{array}{c}\text { JOURNAL OF THE ACADEMY } \\
\text { OF MARKETING SCIENCE } \\
\text { Volume: } 25 \text { Issue: } 4 \text { Pages:305- } \\
318\end{array}$ \\
\hline 258 & $\begin{array}{l}\text { Lazonick, W; } \\
\text { O'Sullivan, M }\end{array}$ & $\begin{array}{l}\text { Maximizing shareholder value: a } \\
\text { new ideology for corporate } \\
\text { governance }\end{array}$ & $\begin{array}{l}\text { ECONOMY AND SOCIETY } \\
\text { Volume: } 29 \text { Issue: } 1 \text { Pages:13-35 }\end{array}$ \\
\hline 195 & $\begin{array}{l}\text { Chatterjee, S; } \\
\text { Lubatkin, Mh; } \\
\text { Schweiger, Dm; }\end{array}$ & $\begin{array}{c}\text { Cultural-Differences And } \\
\text { Shareholder Value In Related } \\
\text { Mergers }\end{array}$ & $\begin{array}{l}\text { STRATEGIC MANAGEMENT } \\
\text { JOURNAL Volume: } 13 \text { Issue: } 5 \\
\text { Pages:319-334 }\end{array}$ \\
\hline 166 & Payne, A; Frow, P & $\begin{array}{l}\text { A strategic framework for customer } \\
\text { relationship management }\end{array}$ & $\begin{array}{c}\text { JOURNAL OF MARKETING } \\
\text { Volume: } 69 \text { Issue: } 4 \text { Pages:167- } \\
176\end{array}$ \\
\hline 154 & $\begin{array}{l}\text { Thomsen, S; } \\
\text { Pedersen, T }\end{array}$ & $\begin{array}{l}\text { Ownership structure and economic } \\
\text { performance in European companies }\end{array}$ & $\begin{array}{l}\text { STRATEGIC MANAGEMENT } \\
\text { JOURNAL V:21 I } 6 \text { Pg:689-705 }\end{array}$ \\
\hline 149 & $\begin{array}{l}\text { Brandenburger, } \\
\text { AM; Stuart, H }\end{array}$ & Value-based business strategy & $\begin{array}{c}\text { JOURNAL OF ECONOMICS \& } \\
\text { MANAGEMENT STRATEGY } \\
\text { V5 I1 Pg:5-24 }\end{array}$ \\
\hline 134 & $\begin{array}{l}\text { Hart, SL; Milstein, } \\
\text { MB }\end{array}$ & Creating sustainable value & $\begin{array}{l}\text { ACADEMY OF MANAGEMENT } \\
\text { EXECUTIVE V: } 17 \text { I: } 2 \text { P:56-67 }\end{array}$ \\
\hline 128 & $\begin{array}{l}\text { Hawawini, G; } \\
\text { Subramanian, V; } \\
\text { Verdin, P }\end{array}$ & $\begin{array}{l}\text { Is performance driven by industry- } \\
\text { or firm-specific factors? A new look } \\
\text { at the evidence }\end{array}$ & $\begin{array}{l}\text { STRATEGIC MANAGEMENT } \\
\text { JOURNAL Volume: } 24 \text { Issue: } 1 \\
\text { P:1-16 } \\
\end{array}$ \\
\hline 127 & Beer, M; Nohria, N & Cracking the code of change & $\begin{array}{l}\text { HARVARD BUSINESS REVIEW } \\
\text { Volume: } 78 \text { Issue: } 3 \text { Pages:133-+ }\end{array}$ \\
\hline 107 & $\begin{array}{l}\text { Hendricks, KB; } \\
\text { Singhal, VR }\end{array}$ & $\begin{array}{c}\text { The long-run stock price } \\
\text { performance of firms with effective } \\
\text { TQM programs }\end{array}$ & $\begin{array}{c}\text { MANAGEMENT SCIENCE } \\
\text { Volume: } 47 \text { Issue: } 3 \text { Pages:359- } \\
368\end{array}$ \\
\hline
\end{tabular}

Fonte. Elaborada pelos autores 


\section{Análise descritiva de autores e instituições}

A tabela 16 ilustra os principais autores dos trabalhos obtidos via a pesquisa bibliométrica. Pode-se notar, em alguma medida, dispersão acerca da produção científica sobre o tema, pois os autores mais profícuos não totalizam mais de $2 \%$ dos trabalhos da amostra, e apenas nove autores possuem mais de 3 trabalhos no tema.

Tabela 16 - Autores mais profícuos

\begin{tabular}{|c|c|c|}
\hline Autores & Nro Trabalhos & $\%$ \\
\hline Morgan Na & 6 & $1 \%$ \\
\hline Rego Ll & 5 & $1 \%$ \\
\hline Kumar V & 4 & $1 \%$ \\
\hline Hinterhuber A & 3 & $1 \%$ \\
\hline Leaver A & 3 & $1 \%$ \\
\hline Luo Xm & 3 & $1 \%$ \\
\hline Michalski G & 3 & $1 \%$ \\
\hline Tribo Já & 3 & $1 \%$ \\
\hline Williams K & 3 & $1 \%$ \\
\hline Outros & 375 & $92 \%$ \\
\hline
\end{tabular}

Fonte: Elaborado pelos autores.

A figura 17 mostra a rede de cocitação dos autores, que gerou 3 clusters distintos: o A, que mescla autores tradicionais da estratégia como Michael Porter e Jay Barney com autores da área de economia que geralmente tangenciam temas estratégicos a Teoria da
Agência (Eugene Fama e Michael Jensen); o B, ligado a temas de Marketing e Valor de Marca com Rajenda Srivastava e Philip Kotler; e o C que trata de diversos temas como Organizações, Sociedade, Marketing, etc.

Figura 17 - Diagrama de cocitação de autores

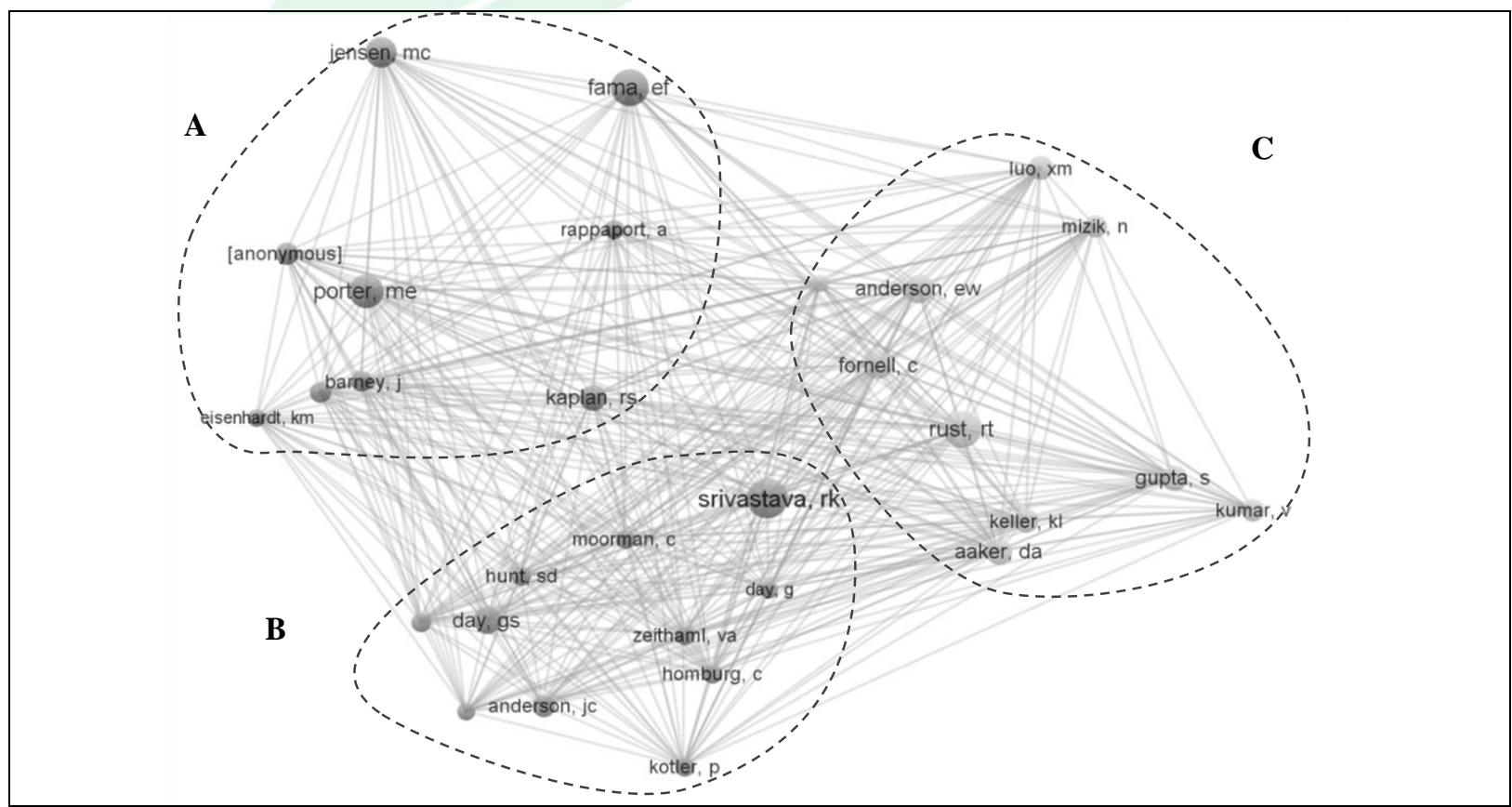

Fonte: Elaborado pelos autores. 
Derivada da análise dos pesquisadores, as tabelas 18 e 19 apresentam as universidades cujos autores mais publicaram no tema, e o respectivo país no qual são sediadas. Excetuando a Wuhan University of

Tabela 18 - Instituições mais profícuas

\begin{tabular}{ccc} 
Organização & Trabalho & \\
Cranfield University & 9 & $2 \%$ \\
\hline Harvard University & 8 & $2 \%$ \\
\hline Indiana University & 8 & $2 \%$ \\
\hline Wuhan Univ Of Technology & 8 & $2 \%$ \\
\hline Indiana University & & \\
Bloomington & 7 & $2 \%$ \\
\hline Indiana University System & 7 & $2 \%$ \\
\hline Insead Business School & 7 & $2 \%$ \\
\hline Pennsylvania Higher Ed & 7 & $2 \%$ \\
\hline University Of Michigan & & \\
System & 7 & $2 \%$ \\
\hline Outros & & 83 \\
& 340 & $\%$ \\
\hline
\end{tabular}

Fonte: Elaborado pelos autores.

O VOSViewer foi empregado para construir um diagrama do relacionamento das instituições, isto é, que universidades são referenciadas nos trabalhos de outras universidades. A figura 20 mostra esta rede, que gerou
Technology sediada na China, as demais se localizam nos polos típicos dos Estados Unidos, Inglaterra (Cranfield) e França (Insead).

Tabela 19 - Países mais profícuos

\begin{tabular}{ccc} 
Países & Nro Trabalhos & $\mathbf{\%}$ \\
\hline Estados Unidos & 168 & $41 \%$ \\
\hline Inglaterra & 53 & $13 \%$ \\
\hline China & 44 & $11 \%$ \\
\hline França & 32 & $8 \%$ \\
\hline Holanda & 32 & $8 \%$ \\
\hline Alemanha & 20 & $5 \%$ \\
\hline Canada & 18 & $4 \%$ \\
\hline Espanha & 13 & $3 \%$ \\
\hline Outros & 28 & $7 \%$ \\
\hline
\end{tabular}

Fonte: Elaborado pelos autores. quatro clusters com o relacionamento dentro de um mesmo cluster de várias universidades de países diferentes.

Figura 20 - Diagrama de relacionamento de universidades

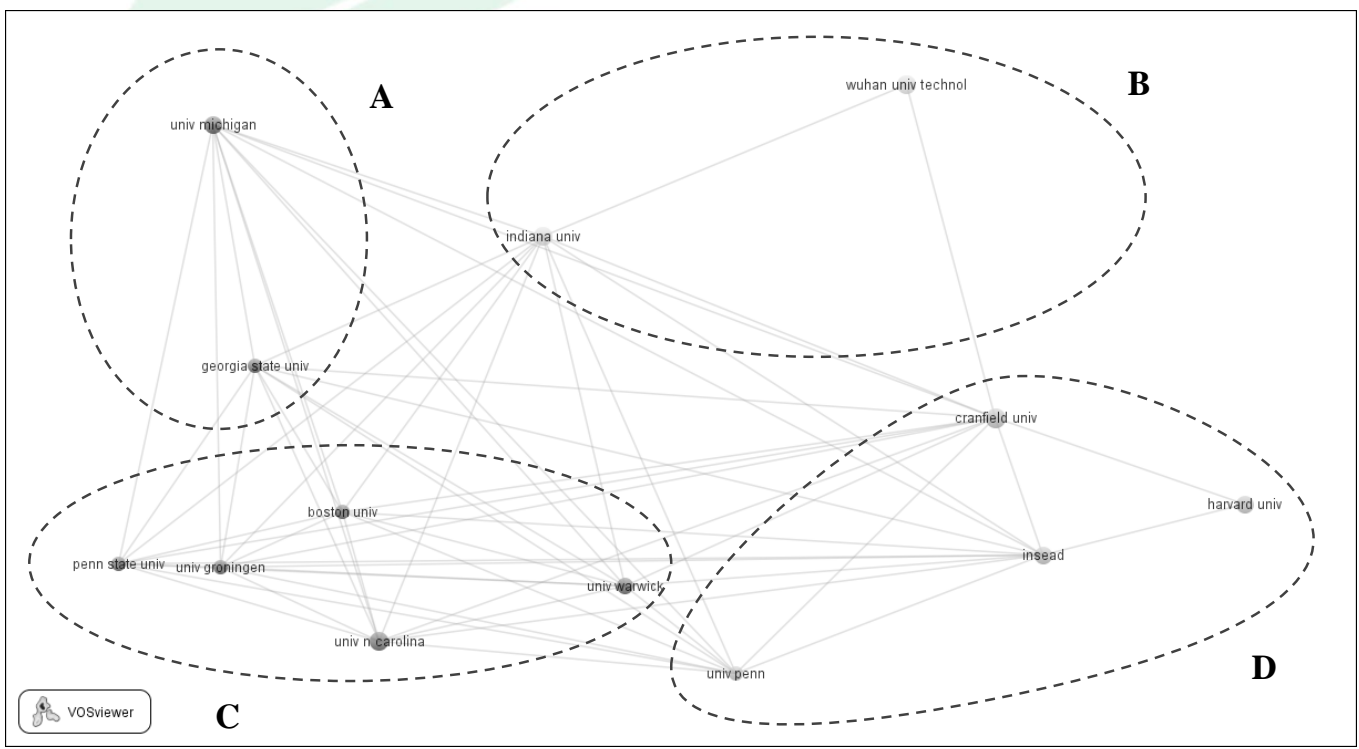

Fonte: Elaborado pelos autores. 


\section{Análise das referências, periódicos e áreas}

A figura 21 mostra a análise de cocitações das referências trazidas na pesquisa bibliométrica. Esta análise busca identificar a quantidade de vezes que dois trabalhos são citados simultaneamente em um mesmo artigo, denotando proximidade temática entre autores e redes de pesquisa. De forma a se extrair maior significado dos resultados, foi estabelecido como $15 \mathrm{o}$ número mínimo de referências aos artigos. Foram produzidos três clusters distintos; (1) o A, com trabalhos clássicos de Estratégia e Visão Baseada em Recursos, com Porter, Prahalad, Barney, Wernerfelt, etc.; (2) B, ligado a temas de marketing e geração de valor, com os trabalhos de Srivastava, Gupta e (3) o C, também com temas de Marketing e Geração de Valor, mas aparentemente segredados pelo espaço de tempo, pois compreendem trabalhos da década de 90 , enquanto o cluster B abarca trabalhos posteriores ao ano 2000.

Figura 21 - Diagrama de Cocitações (mínimo 15 referencias)

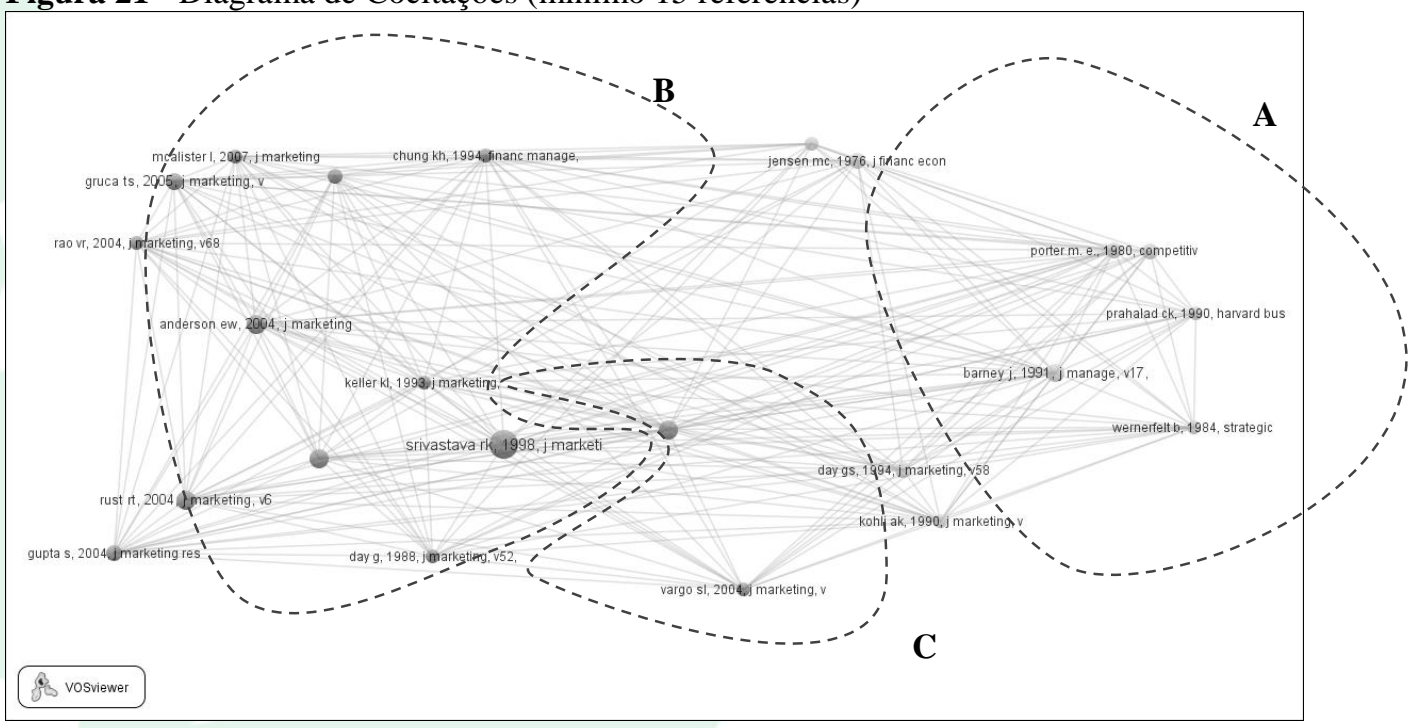

Fonte: Elaborado pelos autores.

A tabela 22 apresenta os periódicos nos quais os artigos mais referenciados pelos trabalhos da pesquisa foram publicados. Pode-se observar também certa dispersão nos periódicos que veiculam as publicações, pois os cinco principais periódicos somam apenas $20 \%$ das publicações.

Tabela 22 - Periódicos mais citados

\begin{tabular}{|c|c|c|}
\hline Periódicos & Nro Trabalhos & $\mathbf{\%}$ \\
\hline Journal Of Marketing & 22 & $5 \%$ \\
\hline Harvard Business Review & 18 & $4 \%$ \\
\hline Industrial Marketing Management & 15 & $4 \%$ \\
\hline Journal Of The Academy Of Marketing Science & 14 & $3 \%$ \\
\hline Strategic Management Journal & 11 & $3 \%$ \\
\hline Journal Of Business Ethics & 7 & $2 \%$ \\
\hline Journal Of Business Research & 7 & $2 \%$ \\
\hline Management Decision & 6 & $1 \%$ \\
\hline Outros & 308 & $75 \%$ \\
\hline
\end{tabular}

Fonte: Elaborado pelos autores.

Foi construído, na figura 23, um diagrama de cocitação dos periódicos, ilustrando quais periódicos são tipicamente referenciados juntos. Três clusters foram obtidos: (1) o A, com periódicos clássicos de finanças e economia, como o Journal of Political Economy, American Economy Review, Journal of Finance; (2) o B com os periódicos de estratégia e gestão (Strategic Management Journal, Academy of 
Management Review, etc); e (3) o C, com periódicos clássicos de Marketing (como Journal of Marketing, Journal of Marketing Research).

Figura 23- Diagrama de cocitação de periódicos (min 65)

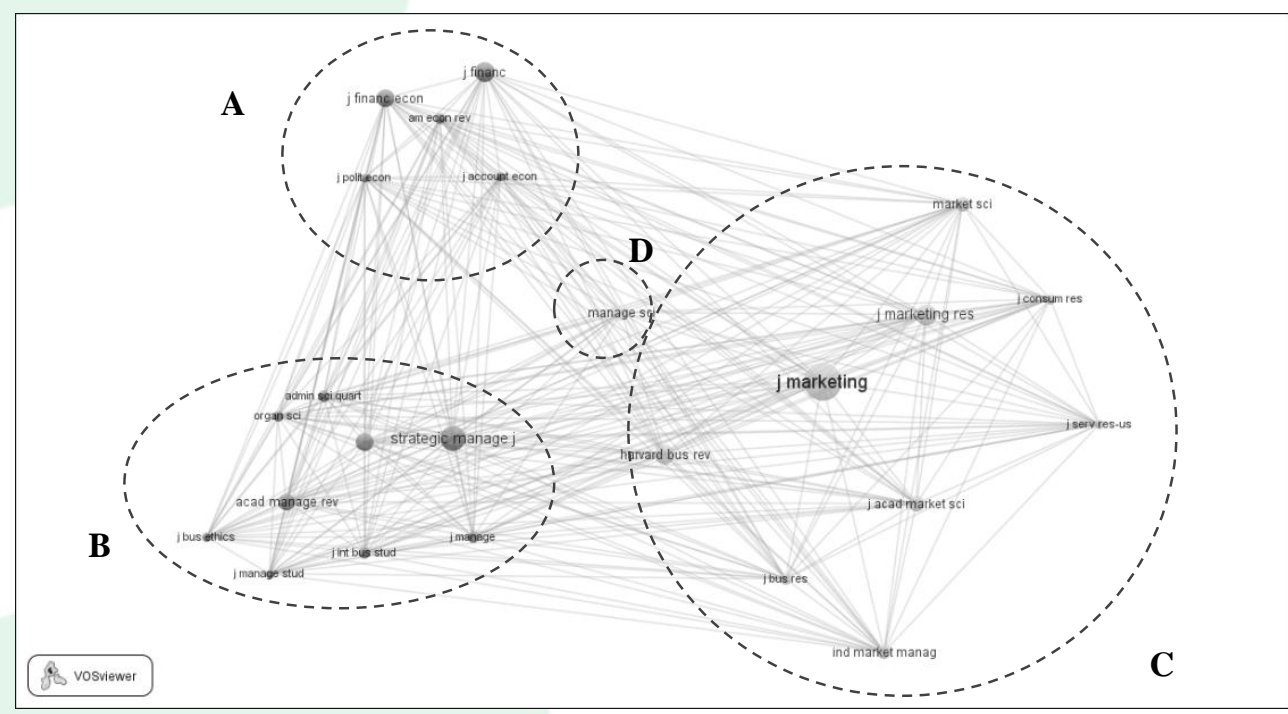

Fonte: Elaborado pelos autores.

\section{Análises de Termos e Palavras-Chave}

A figura 24 traz a frequência das palavras-chave nos artigos obtidos por meio desta pesquisa bibliométrica. Diferentemente da primeira pesquisa, as frequências de palavras-chave são significativamente superiores, com 31 para Valor ao Acionista, e média de 10 para as demais. Dentre as demais, temos temas de estratégia e gestão (Performance, Strategy), Valor (Value, Customer Value) e Finanças e Governança Corporativa.

Figura 24- Frequência das palavras-chave

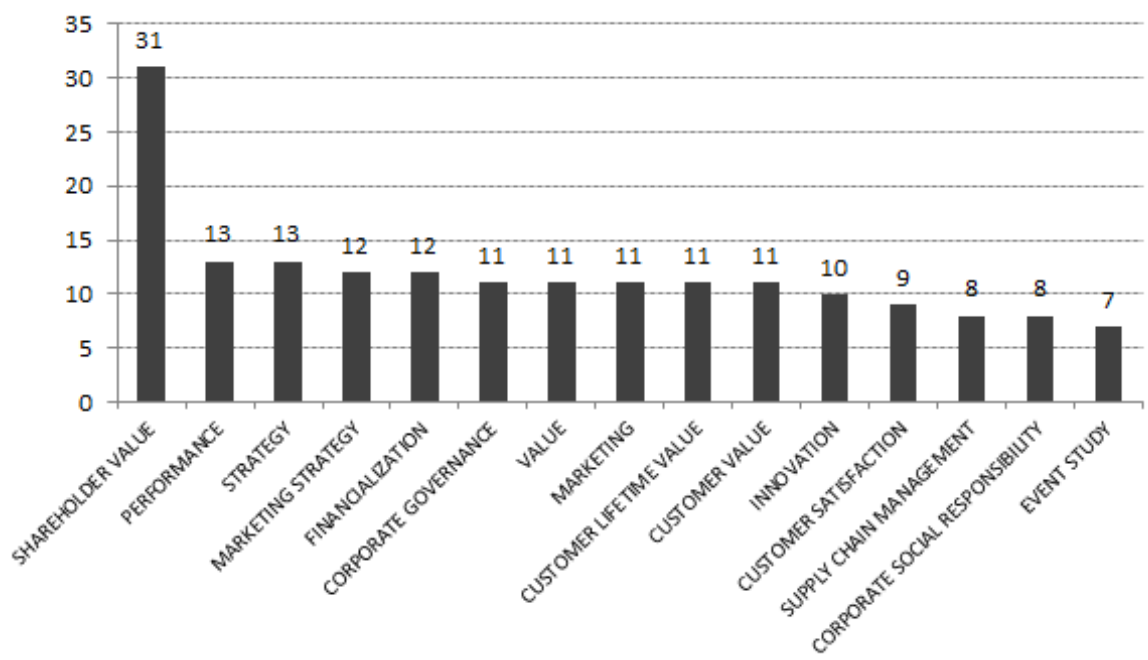

Fonte: Elaborado pelos autores.

Utilizando a função de identificação de termos do VOSViewer, que busca termos tanto no título quanto no resumo dos artigos, foi construído o diagrama de relacionamento de termos da figura 25, sendo 
Estratégia e Valor os termos mais presente. Neste mesmo diagrama puderam ser obtidos três clusters distintos: (1) o A, que aparentemente trata temas de estratégia e negócios (strategy, company, business), e (2) o B, centralizado no termo Valor, e (3) o C, tratando de Desempenho, Resultados e Firma.

Figura 25 - Diagrama de relacionamento de termos

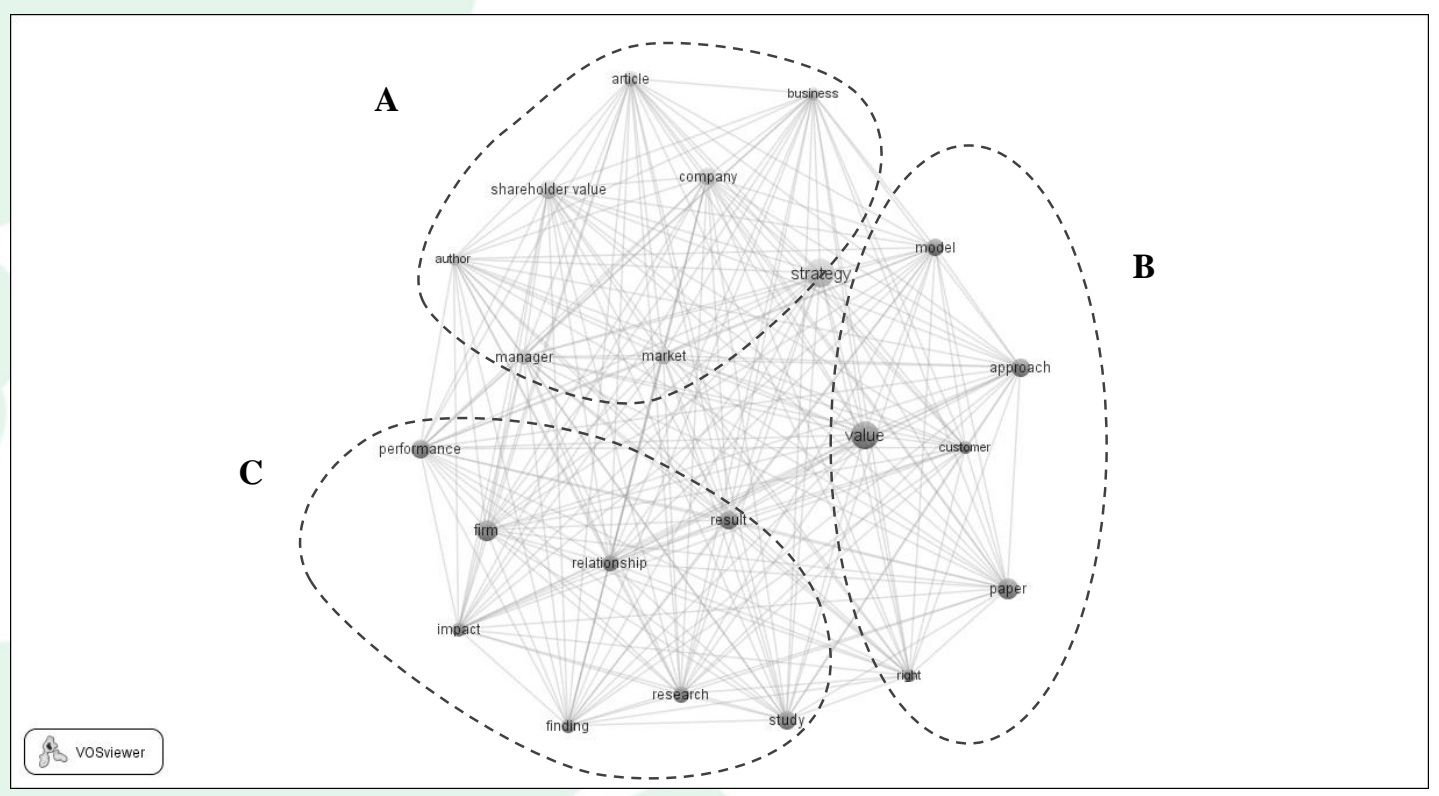

Fonte: Elaborado pelos autores.

\section{Discussão dos resultados}

Uma vez reorientada a pesquisa por meio da incorporação de termos auxiliares relativos à Geração de Valor ao Acionista, foi obtida uma amostra bastante mais representativa, contendo 408 trabalhos.

Um dos primeiros resultados derivado da análise da amostra é que a produção acadêmica no tema cresce a partir de 2008, dado que esse período concentra $63 \%$ do total das publicações, com uma média de 42,5 publicações por ano. Similarmente, a quantidade de citações também se incrementa substancialmente a partir de 2008, período que congrega $81 \%$ das citações com uma média de 652 citações por ano.

As principais publicações mais citadas dentro da amostra, conforme seria de esperar, se centram no tema de Geração de Valor ao Acionista, mas também trazem algumas aplicações específicas dentro de administração, como temas relativos ao Marketing e a Gestão de Mudanças - denotando o quanto estes temas podem se aproximar de aspectos da estratégia. Ao analisar os principais periódicos nos quais estes principais artigos são citados, tem-se que, diferentemente da primeira versão, estes geralmente estão centrados em periódicos sobre Estratégia (Strategic Management Journal, Journal of Economics e Management Strategy) e sobre Gestão (Harvard
Business Review, Management Science, Academy of Management) e outros sobre Marketing e Economia.

Acerca dos autores, pôde ser identificada dispersão acerca da produção científica sobre o tema, pois os autores mais profícuos não totalizam mais de $2 \%$ dos trabalhos da amostra. A análise de cocitação dos autores também traz insights interessantes, na medida em que se obteve um cluster "purista" de estratégia (com todas as reservas que este termo pode ensejar) com autores clássicos da área como Porter e Barney, um cluster bastante relevante com temas de Marketing e Valor de Marca (novamente ressaltando a relevância e conexão desses temas com a estratégia) e um último tratando de aspectos mais contextuais da estratégia como Organizações e Sociedade.

A análise das universidades chama a atenção para a aparição da Wuhan University of Technology, universidade chinesa fora da rota tradicional de Estados Unidos ou Europa para publicação. Das análises dos países, além da China, também se destaca a presença relevante de Holanda (8\%), Alemanha (5\%) e Espanha (3\%), que geralmente não figuram como principais origens de pesquisa na área. $\mathrm{O}$ diagrama de relacionamento (figura 20) também indica que parece não haver "regionalização" dessas universidades, dado que fica evidenciado o relacionamento dentro de um mesmo cluster de várias universidades de países diferentes. 
A análise das referências, por meio de cocitações, também produziu resultados interessantes. Em linha com o resultado da clusterização dos autores, a cocitação das referências também produziu um cluster "purista" (com as mesmas reservas) e reforçou a relevância dos temas de Marketing e Geração de Valor.

Observando os periódicos nos quais tal pesquisa tem sido publicada, fica reforçada a dispersão da pesquisa, e também a relevância de temas vinculados ao Marketing para a relação finanças e estratégia, em análise. Isso reforça a relevância do Marketing, conforme já mencionado acima, o que também é corroborado pelas palavras-chave, dado que as palavras-chave Estratégia de Marketing, Satisfação de Clientes, Ciclo de Vida de Consumidores, etc. também apareceram com frequência representativa.

\section{CONCLUSÕES E CONSIDERAÇÕES FINAIS}

Retomando o objetivo original deste trabalho, este buscava realizar uma pesquisa bibliométrica sobre a Financeirização da Estratégia, para avaliar aspectos como principais trabalhos, autores, local de publicação, temas e palavras-chave sobre pesquisas, de forma a elaborar um panorama inicial sobre a referida área. A base de dados Web of Science da Thomson Reuters foi utilizada, em conjunto com o software VOSViewer.

A primeira tentativa, utilizando apenas as palavras-chave "financialization" e "strategy" não atinge os objetivos, pelo baixo número de publicações e citações obtidas, e pelo foco geral (tanto dos temas quanto dos canais de publicação) em Economia e não em Estratégias Empresarias. A pesquisa assim foi reorientada para incorporar também palavras-chave relacionadas à financeirização, como Geração de Valor ao Acionista, gestão baseada em valor, e ferramentas como o EVA (Economic Value Added). Esta reorientação produziu uma amostra maior e mais representativa, permitindo assim a consecução de análises alinhadas ao objetivo deste artigo.

$\mathrm{O}$ fato mencionado no parágrafo acima talvez seja a primeira conclusão do próprio trabalho. Embora exista uma quantidade representativa e interessante de pesquisas sobre o processo de Financeirização das Estratégias, estas não estão sendo realizadas sobre o rótulo de Financeirização propriamente dito. Tal rótulo, como visto, geralmente fica reservado para pesquisas relacionadas a aspectos econômicos amplos como capitalismo, neoliberalismo, etc.

Uma vez realinhada a pesquisa, as demais conclusões podem ser estabelecidas com base nos dados apresentados na seção anterior.

Segundo, embora o processo de financeirização tenha suas raízes em teoria econômica anterior, o estudo da Financeirização da Estratégia é relativamente recente, com aumento de produção acadêmica a partir do ano de 2008. Valendo recordar que também, do ponto de vista econômico, a partir deste ano ocorre o incremento das pesquisas que buscam entender e explicar a crise mundial originada a partir da crise do sub-prime americana.

Terceiro, a questão da Geração de Valor ao Acionista parece ser o tema central nas pesquisas relacionadas à Financeirização da Estratégia, fato que fica evidenciado tanto pela listagem das publicações mais citadas (tabela 9) quanto das principais palavraschave. Além disso, uma série de outros temas parece "orbitar" ao longo da Geração de Valor ao Acionista nas pesquisas: geração de valor sustentável, valor de marca e ativos de mercado.

Quarto, a pesquisa na área parece ser bastante dispersa, pois não se identifica um autor, ou conjunto de autores, que seja extremamente expressivo na área (do inglês, um must-read). Além disso, embora os Estados Unidos seja o país com maior produção na pesquisa, a produção é bastante distribuída entre as diversas universidades, e a produção de países e universidades europeus e também da China é relevante.

Quinto, os principais canais de publicação destas pesquisas também são dispersos, e além de periódicos voltados a finanças e à estratégia (novamente com a ressalva de aqui se entender estratégia como o campo tradicional das Estratégias Empresariais, embora todas as contribuições das funções da empresa possam ser estratégicas também), tal pesquisa também é veiculada em jornais de marketing. Esse fato chama a atenção e gera a demanda por uma melhor compreensão de como as pesquisas geralmente correlacionam temas específicos de marketing, como valor de marca, satisfação e lealdade de clientes, à geração de valor - atribuindo a estes termos grande relevância nesta inter-relação entre finanças e estratégia.

Com estas conclusões preliminares da pesquisa, desdobra-se uma agenda para possíveis pesquisas futuras. Primeiro, este estudo se embasa em outras pesquisas para considerar que a Geração de Valor ao Acionista é o principal impacto da Financeirização sobre as Estratégias Empresariais. São necessárias novas pesquisas para poder identificar que outros impactos também podem ser decorrentes da financeirização. Por exemplo, temas como Gestão de Riscos, Modelos de Governança e aspectos voltados ao perfil de Recursos Humanos dos gestores precisam ser explorados e mais bem explicados nesse contexto. Segundo, além dos aspectos "diretos" da Financeirização sobre as firmas, tal processo também impacta outros agentes macroeconômicos e esses devem ter um impacto "indireto" também sobre as firmas. Nessa linha, novas pesquisas podem buscar compreender como aspectos de Desregulamentação de Mercados, Fluxos Internacionais de Capitais, e alterações no Sistema Bancário impactam as firmas e, portanto, suas estratégias. Terceiro, ao expandir o conceito de estratégia para recursos e capacidades estratégicos, como os aspectos de valor de marca, 
satisfação de clientes (e outros do Marketing aqui mencionados), é necessário avaliar como os modelos tradicionais de avaliação do valor da firma (Valuation) conseguem capturar tais recursos e capacidades, bem como quais variáveis exógenas influenciam a relação entre tais capacidades e o valor da empresa. Quarto, esta pesquisa se ocupou da conexão entre estratégia e financeirização, um tema financeiro. Outras pesquisas podem buscar trabalhar a conexão da estratégia com aspectos de outras funções, como os Recursos Humanos, o Marketing, Operações e Supply Chain, entre outros.

Por fim, vale um comentário acerca da própria relevância de estudos bibliométricos como este. Como destaca Mugnaini (2006), a importância de estudos bibliométricos deriva da necessidade de avaliar a produtividade e a qualidade da pesquisa dos diversos atores acadêmicos, detectando modelos e padrões de comportamento em sua produção científica. Estes modelos e padrões ajudam a compreensão de como o conhecimento científico se difunde e se incorpora entre estes diversos autores, permitindo quantificar a produção e identificar áreas de excelência acadêmica (Ravelli, Fernandes, Barbosa, Simão \& Meirelles, 2009, Carvalho, 2005 e Fillipo, 2002). Justamente por isso, a relevância dos estudos bibliométricos reside em caracterizações que privilegiam a abrangência com algum detrimento da profundidade, criando grandes panoramas de pesquisa que permitem o posterior trabalho enfocado nas diversas lacunas e oportunidades de pesquisa identificadas por tais estudos. Além de sua própria relevância, entende-se que estudos bibliométricos possuem um caráter "facilitador" da

\section{REFERÊNCIAS}

Andersson, T., Haslam, C., Lee, E., \& Tsitsianis, N. (2008) Financialization directing strategy. Accounting Forum, 32, pp. 261-275.

Andersson, T., Haslam, C., Lee, E., Katechos, G., \& Tsitsianis, N. (2010) Corporate strategy financialized: Conjuncture, arbitrage and earnings. Accounting Forum, 34, pp. 211-221.

Bailey, K. (1994). Methods of Social Research. Free Press, 1994.

Bird, A., \& Beechler, S. (1995). Links between business strategy and human resource management strategy in US-based Japanese subsidiaries: An empirical investigation. Journal of International Business Studies, 23-46. contribuição e relevância dos trabalhos que deles derivam.

Assim como qualquer trabalho de revisão bibliométrica, principalmente aqueles que se ocupam de fazer um mapeamento geral de área de pesquisa, este deve ser tomado com plena ciência de suas limitações. Primeiro, a restrição da base de pesquisa escolhida, que não representa toda a produção científica da área. Nesta pesquisa se optou pela Web of Science, que embora tenha periódicos de excelente qualidade, consegue capturar pouco de pesquisas que ainda estão em processo de elaboração (como seria uma pesquisa usando o Google Scholar, por exemplo). Segundo, possibilidades de erros na padronização dos campos (ex. autores, periódicos etc.) o que pode levar a conclusões parcialmente incorretas. Como exemplo, grafias ligeiramente distintas para uma mesma universidade fará com que os sistemas de análise a considerem como duas instituições distintas, o que de alguma forma enviesará a análise. Terceiro, a presente abordagem de pesquisa optou por realizar uma análise amparada em uma amostra obtida aleatoriamente de uma base de dados indexada. Uma alternativa diferente seria a definição de um grupo específico de periódicos dentro dos quais se conduziria a pesquisa bibliométrica. Embora na primeira abordagem exista o benefício da amostra ao acaso, sem viés, uma amostra dirigida também pode acabar obtendo respostas melhores na medida em que direciona para periódicos mais representativos ao tema em questão. Por fim, deve-se tomar em consideração o próprio caráter generalista de trabalhos bibliométricos que, em virtude de sua escolha e recorte de pesquisa, são conduzidos em detrimento de trabalhos com questões mais específicas.

Borgatti, S.P., Everett, M.G., \& Freeman, L.C. (1999) UCINET 6.0 Version 1.00, Analytic Technologies, Natick.

Brown, J. R., Fazzari, S.M., \& Petersen, B. C. (2009) Financing innovation and growth: Cash flow, external equity, and the 1990s R\&D boom. The Journal of Finance, 64(1), pp. 151-185.

Bryman, A.(1989) Research methods and organization studies. London: Unwin Hyman.

Chesnais, F. (2002). A teoria do regime de acumulação financeirizado: conteúdo, alcance e interrogações. Economia e Sociedade, 11(1), 144.

Chesnais, F. (2008). Mundialização: o capital financeiro no comando.Outubro, 5, 7-28. In: Caderno de Textos do II Seminário Livre pela Saúde, Belo Horizonte. 
Chu, D., \& Andreassi, T. (2011) Management of technological innovation: Case studies in biotechnology companies in Brazil. Management Research: The Journal of the Iberoamerican Academy of Management, 9(1), pp. 7-31.

Corsatto, C. A., (2010) Gestão da Inovação no Processo de Desenvolvimento de Software: o caso das empresas do APL de Tecnologia da Informação de Goiania-GO. Dissertação de Mestrado. Universidade Federal de São Carlos.

Crossan, M. M., \&Apaydin, M. (2010) A multidimensional framework of organizational innovation: A systematic review of the literature. Journal of Management Studies, 47(6), pp. 11541191.

Dias, A. V. C, \& Zilbovicius, M.(2006) A produção face à financeirização: quais consequências para a organização da produção e do trabalho? Uma proposta de agenda de pesquisa para a Engenharia de Produção brasileira. XXVI ENEGEP - Encontro Nacional de Engenharia de Produção. Anais do XXVI ENEGEP, Fortaleza.

DiMaggio, P. (Ed.). (2009). The twenty-first-century firm: changing economic organization in international perspective. Princeton University Press.

Dervitsiotis, K. N. (2010) A framework for the assessment of an organisation's innovation excellence. Total Quality Management, 21(9), pp. 903-918.

Dubé, L., \&Paré, G. Rigor in information systems positivist case research: current practices, trends, and recommendations. MIS Quarterly, 27(4), pp.597-635.

Ehrbar, A. (1999) Eva Valor Econômico Agregado: a verdadeira chave para a criação de riqueza. Rio de Janeiro: Qualitymark.

Eisenhardt, K. M. (1989) Building theories from case study research. Academy of Management, 14(4), pp.532-550.

Epstein, G. A. (Ed.). (2005). Financialization and the world economy. Edward Elgar Publishing.

Fligstein, N. (2002) The architecture of markets: An economic sociology of twenty-first-century capitalist societies. Princeton: Princeton University Press.
Froud. J, Johal, S., Leaver, A., \&Williams, K. (2006) Financialization and Strategy: Narrative and Numbers. Routledge.

Froud, J., Johal, S., Leaver, A., \& Williams, K. (2012). Apple business model: Financialization across the Pacific. CRESCWorking Paper, (111).

Gay, L. R., Diehl, P. L. (1992) Research Methods for business and Management. Maxwell Macmillan, Estados Unidos.

Gil, A. C. (!999) Métodos e Técnicas de Pesquisa Social. Quinta Edição, Ed. Atlas.

Guedes, V. L. S., \&Borschiver, S. (2005) Bibliometria: Uma Ferramenta Estatística Para a Gestão da Informação e do Conhecimento, em Sistemas de Informação, de Comunicação e de Avaliação Científica e Tecnológica. Anais do VI CINFORM Encontro Nacional da Ciência da Informação. Salvador.

Guerrazzi, L. A., Brandão, M. M., de Campos Junior, H., \& Lourenço, C. E. (2015). Pesquisa em Marketing e Estratégia nos Principais Periódicos Internacionais: Um Estudo Bibliométrico sobre Publicações no Século XXI. Revista Ibero-Americana de Estratégia, 14(1), 7.

Hall, B. H. (2005) The financing of innovation. The Handbook of Technology and Innovation Management, pp. 409-430.

Hall, B. H., Lerner, J. (2009) The financing of $R \& D$ and innovation. National Bureau of Economic Research.

Hansen, M. T., \&Birkinshaw, J. (2007) The innovation value chain. Harvard business review, 85(6), p. 121.

Hayes, R. H., \&Wheelwright, S. C. (1984) Restoring our competitive edge: competing through manufacturing. New York: Wiley.

Jacobson, R. (1992) The "Austrian" school of strategy. Academy of management review, 17(4), p. $782-807$.

Jarzabkowski, P., Balogun, J., \&Seidl, D. (2007) Strategizing: The challenges of a practice perspective. Human Relations, 60(1), pp. 5-27.

Johnson, G., Langley, A., Melin, L, \&Whittington, R. (2007) Strategy as Practice: Research directions and resources. Reino Unido: Cambridge University Press. 
Johnson, G., Melin, L., \&Whittington, R. (2003) Micro Strategy and Strategizing: Towards an activity-based view. Journal of Management Studies, 40 (1), pp. 3-22.

Kline, S. J., \&Rosenberg, N. (1986) An overview of innovation. The positive sum strategy: Harnessing technology for economic growth, 14, p. 640.

Koller, T., Goedhart, M., \&Wessels, D. (2010) Valuation: measuring and managing the value of companies. 5th Edition, Wiley.

Lazonick, W., \&O'Sullivan, M.. (2000) Maximizing shareholder value: a new ideology for corporate governance. Economy and society, 29(1), pp. 1335 .

Lazzarini, S. G. (1997) Estudos de caso: aplicações e limites do método. In: FARINA, E. Estudos de caso em agribusiness. São Paulo: Pioneira.

Maia, J. L. (2010) Gestão Competitiva em Empresas Brasileiras: a prática da estratégia por meio de suas visões, ferramentas e atores do processo. Tese de Doutorado (Engenharia de Produção). Universidade Federal de São Carlos.

Maia, J.L. , \&Di Serio, L. C. (2014) Financialization and Business Strategy: the need for bridging efforts In: POMS 25th Annual Conference, Estados Unidos.

Maia, J.L. , \&Di Serio, L. C. (2014) Exploração da Literatura sobre o processo de financeirização da estratégia (e conceitos relacionados) por meio de análise bibliométrica In: XVII Simpósio de Administração da Produção, Logística $e$ Operações Internacionais - SIMPOI 2014, 2014, São Paulo.

Martin, J. D., \&Petty, J. W. (2001) Value Based Management: The Corporate Response to the Shareholder Revolution, Oxford University Press.

Mugnani, R.(2006) Caminhos para adequação da avaliação da produção científica brasileira: impacto nacional versus internacional [tese]. São Paulo (SP): Universidade de São Paulo.

Neely, A. (2005) The Evolution of Performance Measurement Research. International Journal of Operations \& Production Management. 25(12), pp. 1264-1277.
OECD. (2005) The Measurement of Scientific and Technological Activities Oslo Manual: Guidelines for Collecting and Interpreting Innovation Data. OECD publishing.

Oke, A. (2007) Innovation types and innovation management practices in service companies. International Journal of Operations \& Production Management, 27(6), pp. 564-587.

Pavitt, K. (2006) Innovation Process. In: FAGERBERG, J., MOWERY, D. C., NELSON, R. R. The Oxford Handbook of Innovation. Oxford Handbooks of Business and Management.

Pritchard, A. (1969) Statistical bibliorgrahy or bibliometricas? Journal of Documentation, 25(4), pp. 348-349.

Ravelli, A.P.X., Fernandes, G. C. M., Barbosa, S. F. F., Simão, E., \&Meirelles, B. H. S. (2009) A produção do conhecimento em enfermagem e envelhecimento: estudo bibliométrico. Texto Contexto Enferm., 18(3), pp. 506- 512.

Richardson, R.J. (1985) Pesquisa Social: método e técnicas. São Paulo, Atlas.

Roesch, S. M. A. (1999) Projetos de Estágio e Pesquisa em Administração. Editora Atlas.

Savignac, F. (2006) The impact of financial constraints on innovation: evidence from French manufacturing firms. Research Report.

Schildt, H.A. (2002) Software for Bibliometric Data Management and Analysis. Helsinki Institute of Strategy and International Business.

Schuler, R. S., \& Jackson, S. E. (1987). Linking competitive strategies with human resource management practices. The Academy of Management Executive (1987-1989), 207-219.

Schumpeter, J. A. (1955) The Theory of Economic Development: An Inquiry into Profits, Capital, Credit, Interest, and the Business Cycle (Social Science Classics Series).

Sheu, D. D., \&Lee, H. (2011) A proposed process for systematic innovation. International Journal of Production Research, 49(3), pp. 847-868.

Slack, N. (2005). Operations strategy: will it ever realize its potential?.Gestão \& Produção, 12(3), 323-332. 
Smit, H. T. J., \&Trigeorgis, L. (2004) Strategic Investment: Real Options and Games. Princeton University Press.

Srivastava, R. K., Shervani, T. A., \& Fahey, L. (1998). Market-based assets and shareholder value: A framework for analysis. The Journal of Marketing, 2-18.

Stockhammer, E. (2012) Financialization. In: Toporowski, J., Michell, J. Handbook of Critical Issues in Finance, Edward Elgar Publishing.

Tidd, J., \&Bessant, J. (2011) Managing innovation: integrating technological, market and organizational change. Wiley.

Vanti, N. (2002) Da Bibliometria à Webometria: uma Exploração Conceitual dos Mecanismos Utilizados para Medir o Registro da Informação e a Difusão do Conhecimento. Ciência da Informação. 31(2), pp. 152-162.

Vasconcellos, L. H. R., Zilbovicius, M. Di Serio, L. C., \&Marx. R. (2007) O consórcio modular sob a ótica do processo de financeirização? Seria este formato organizacional uma das respostas da indústria automotiva? XIV SIMPEP - Simpósio de Engenharia de Produção. Anais do XIV SIMPEP.
Whittington, R. (2002) O que é Estratégia? Tradução de Maria Lúcia Rosa e Martha Malvezzi Leal. São Paulo, Pioneira.

Whittington, R. (2004) Estratégia após o modernismo: Recuperando a prática. RAE Revista de Administração de Empresas, 44(4), pp. 44-53.

Whittington, R. (2006) Completing the practice turn in strategy research. Organization Studies, 27(5), pp. 613-634.

Wood, G., \& Wright, M. (2009). Private equity: A review and synthesis.International Journal of Management Reviews, 11(4), 361-380.

Wong, S., Chin, K. (2007) Organizational innovation management: An organization-wide perspective. Industrial Management \& Data Systems, 107(9), pp. 1290-1315.

Yin, R. (2002) Case study research: Design and methods. SAGE Publications.

Young, S. D. , O’Byrne, S. F. (2001) EVA and valuebased management. New York: McGraw-Hill.

Zinkhan, G. M., \& Verbrugge, J. A. (2000). The marketing/finance interface: two divergent and complementary views of the firm. Journal of Business Research, 50(2), 143-148. 